\title{
Quality-Assurance Plan for the Analysis of Fluvial Sediment by the U.S. Geological Survey Kentucky Water Science Center Sediment Laboratory
}

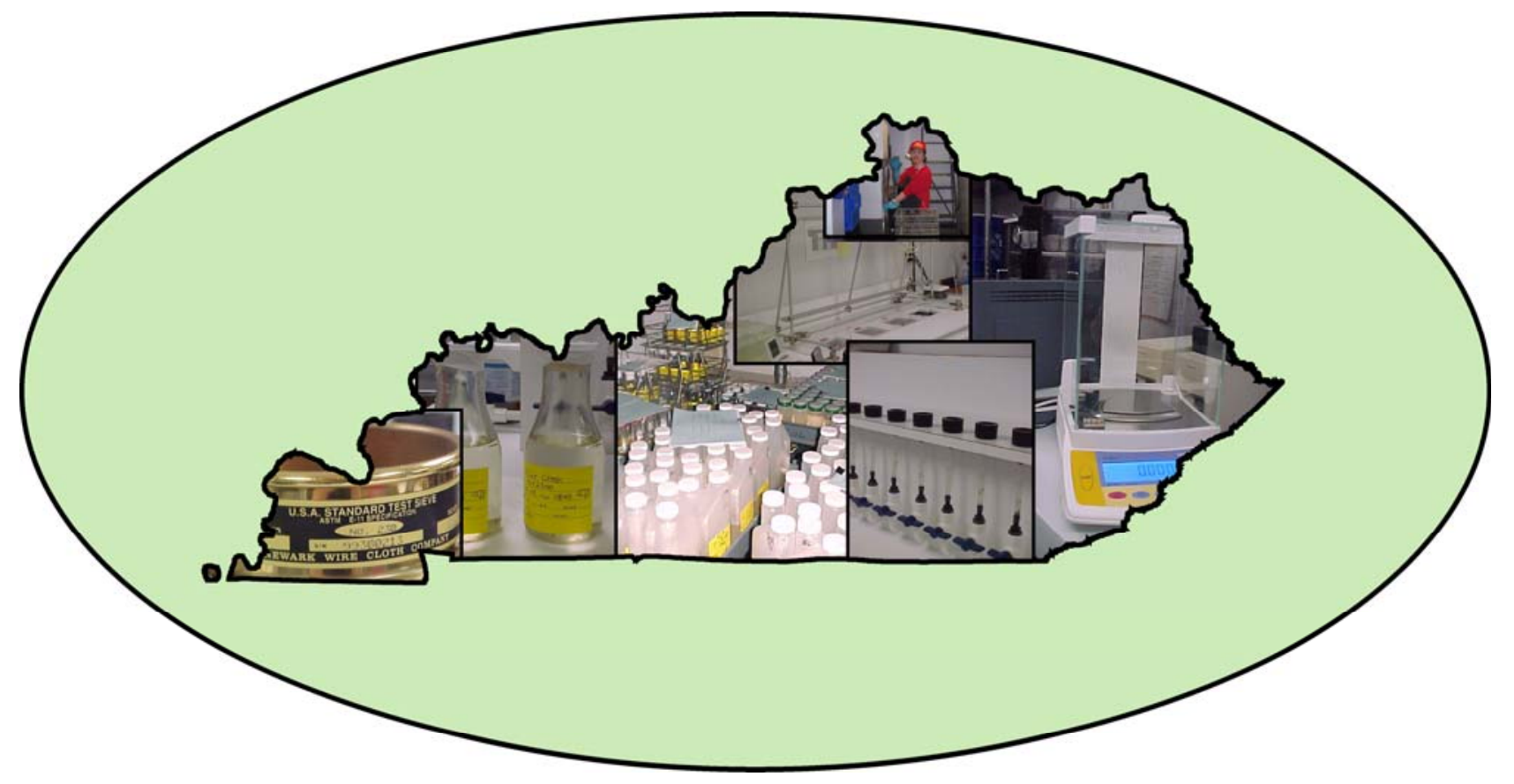

Open-File Report 2005-1230 


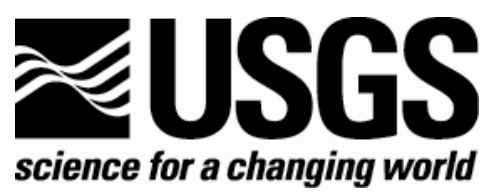

\section{Quality-Assurance Plan for the Analysis of Fluvial Sediment by the U.S. Geological Survey Kentucky Water Science Center Sediment Laboratory}

By Elizabeth A. Shreve and Aimee C. Downs

Open-File Report 2005-1230 


\section{U.S. Department of the Interior \\ Gale A. Norton, Secretary}

\section{U.S. Geological Survey \\ P. Patrick Leahy, Acting Director}

U.S. Geological Survey, Reston, Virginia: 2005

For sale by U.S. Geological Survey, Information Services

Box 25286, Denver Federal Center

Denver, CO 80225

For more information about the USGS and its products:

Telephone: 1-888-ASK-USGS

World Wide Web: http://www.usgs.gov/

This report supersedes Quality-Assurance Plan for the Analysis of Fluvial Sediment by the Northeastern Region, Kentucky District Sediment Laboratory, U.S. Geological Survey Open-File Report 98-384.

Any use of trade, product, or firm names in this publication is for descriptive purposes only and does not imply endorsement by the U.S. Government.

Although this report is in the public domain, permission must be secured from the individual copyright owners to reproduce any copyrighted material contained within this report.

Suggested citation:

Shreve, E.A., and Downs, A.C., 2005, Quality-Assurance Plan for the Analysis of Fluvial Sediment by the U.S. Geological Survey Kentucky Water Science Center Sediment Laboratory: U.S. Geological Survey Open-File Report 2005-1230, 28 p. 


\section{Contents}

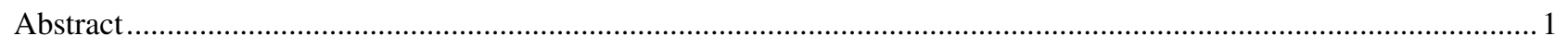

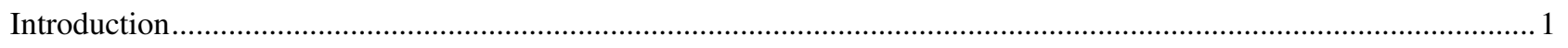

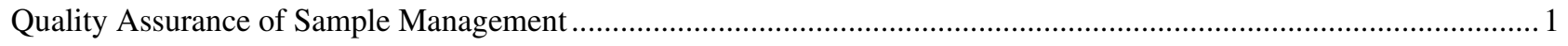

U.S. Geological Survey Sediment Laboratory Analysis Request (SLAR) Form .......................................................2

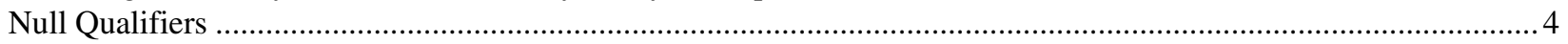

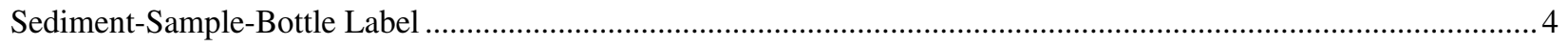

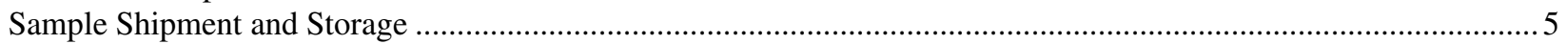

Quality Assurance of Laboratory Equipment and Computer Software...................................................................... 6

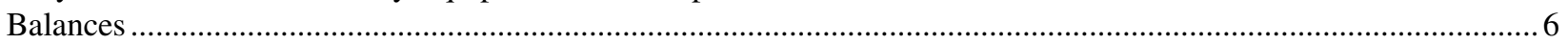

Ovens

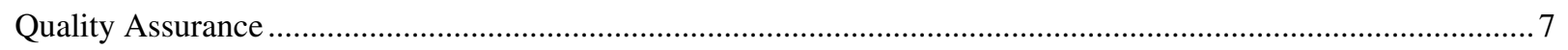

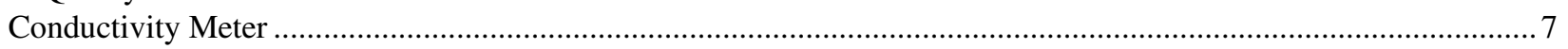

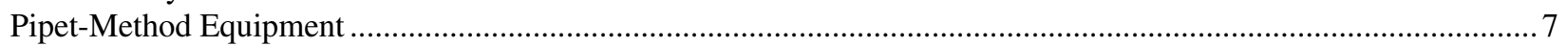

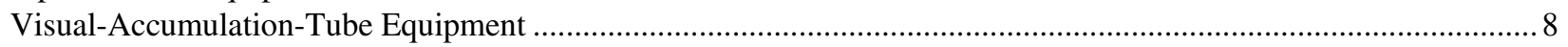

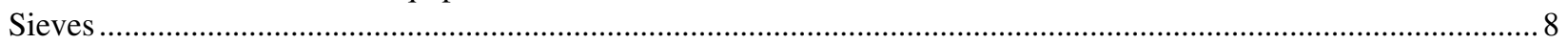

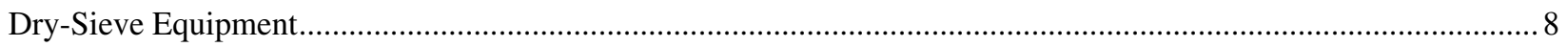

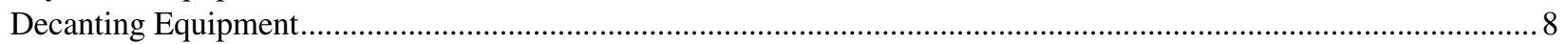

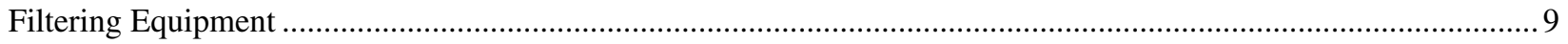

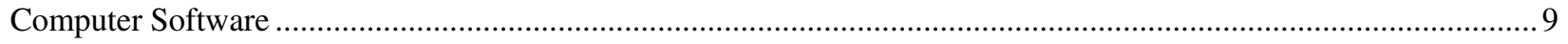

Quality Assurance of Laboratory Apparatus and Standard Solutions .....................................................................

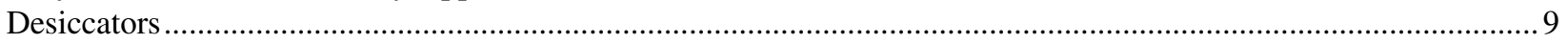

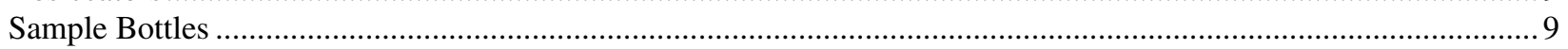

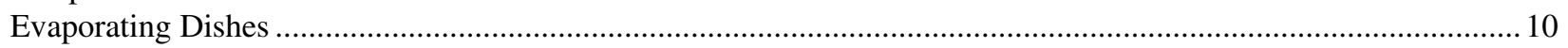

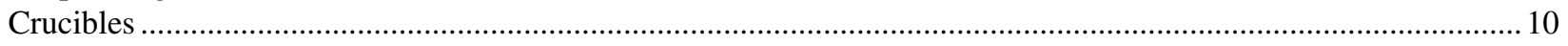

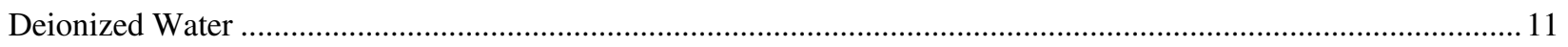

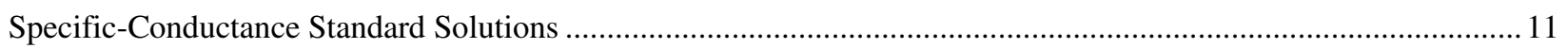

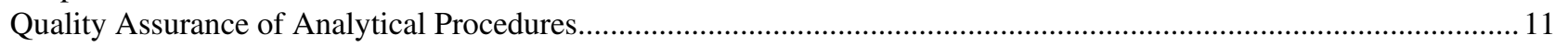

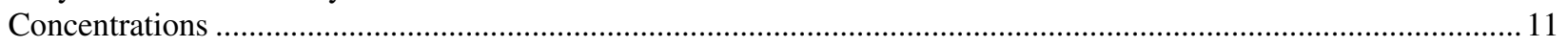

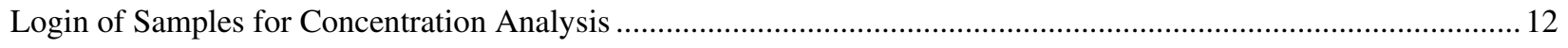

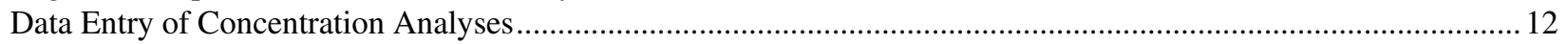

Quality-Control Measures for Data Entry of Concentrations.............................................................................. 13

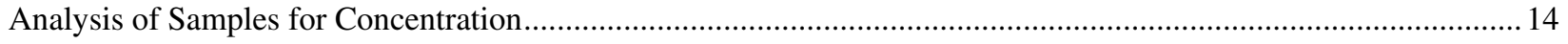

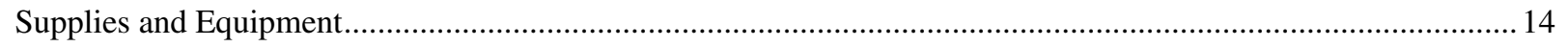

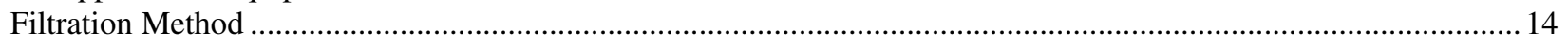

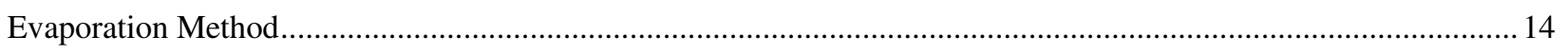

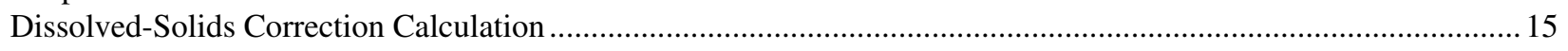

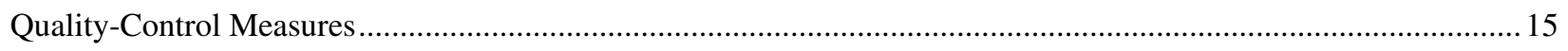

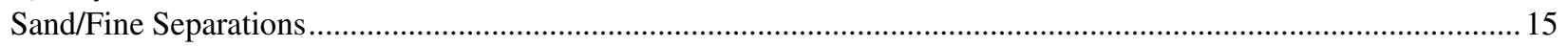

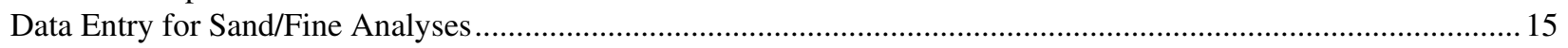

Quality-Control Measures for Data Entry of Sand/Fine Analyses ...................................................................... 16

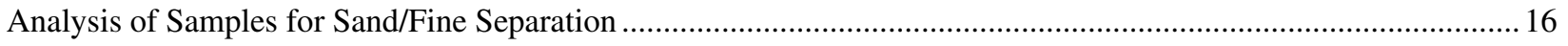

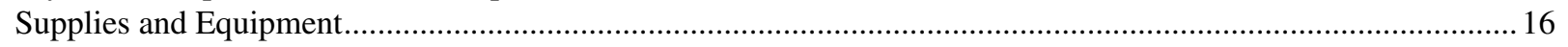

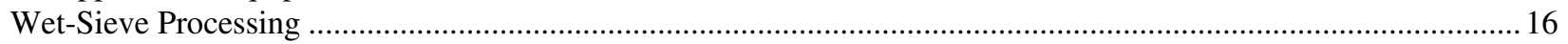

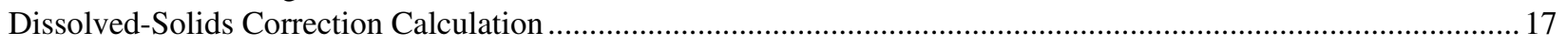

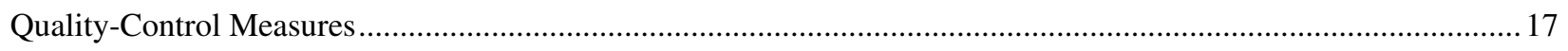

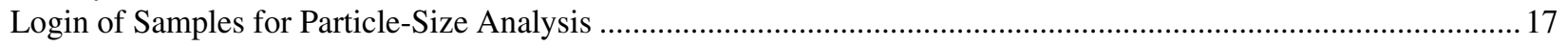

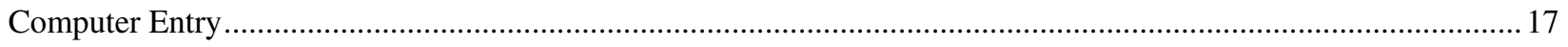

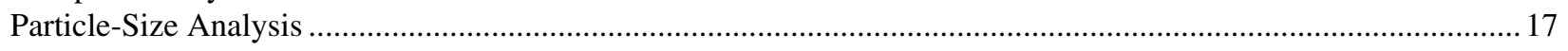




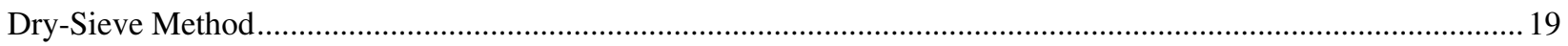

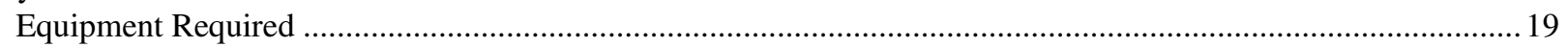

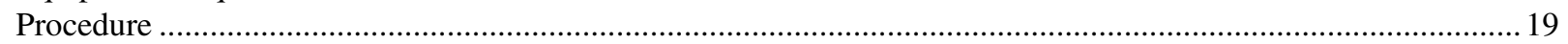

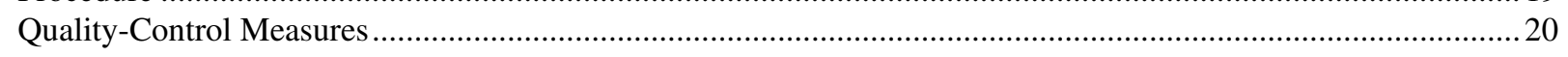

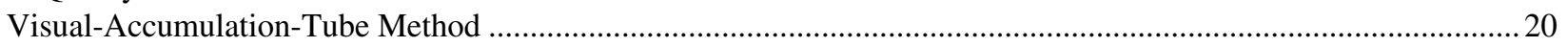

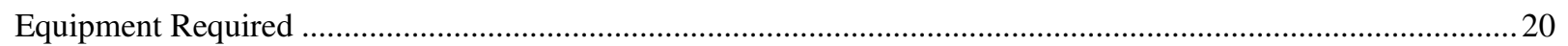

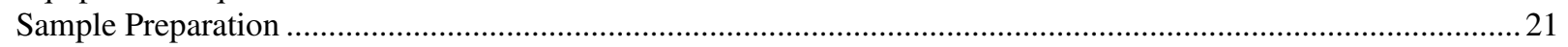

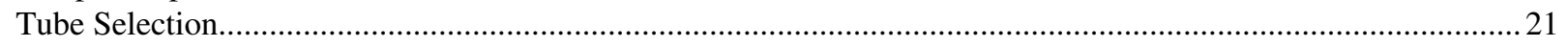

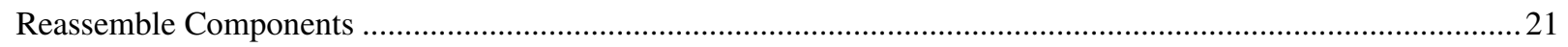

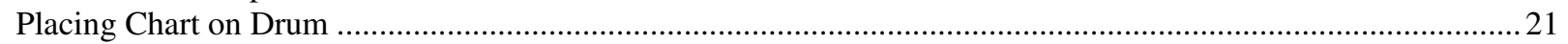

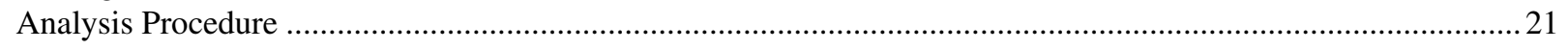

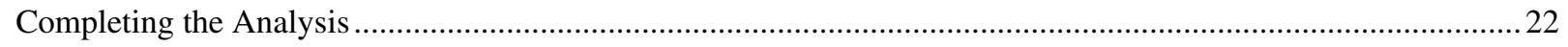

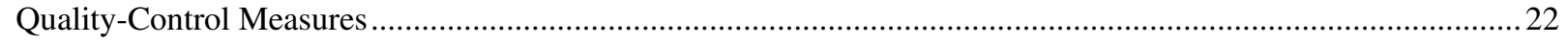

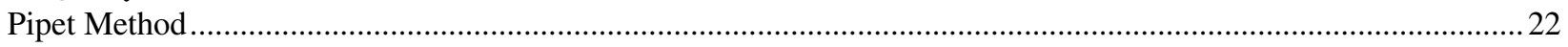

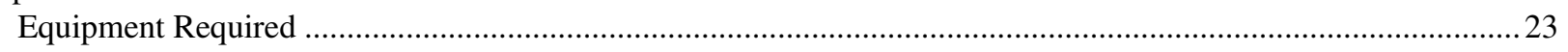

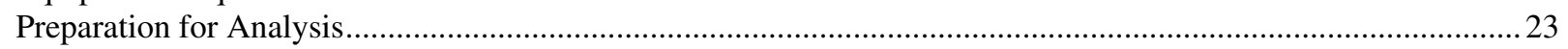

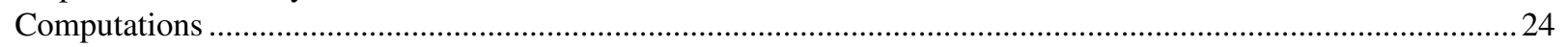

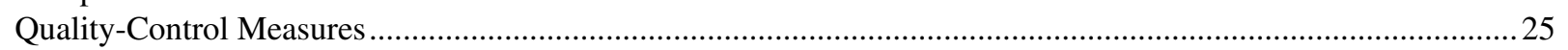

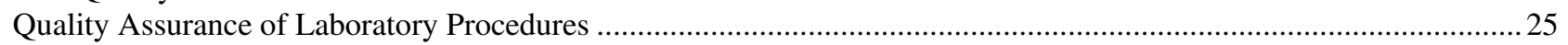

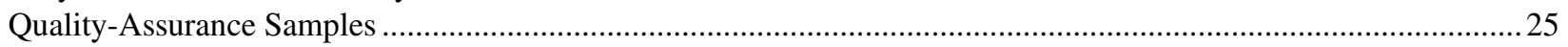

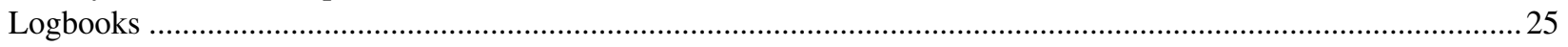

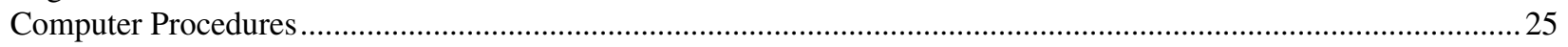

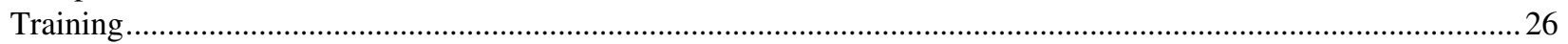

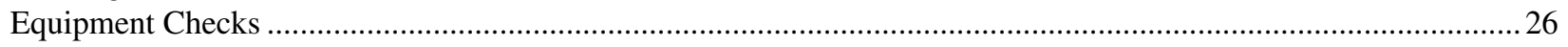

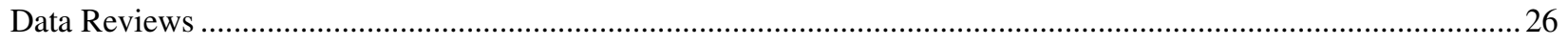

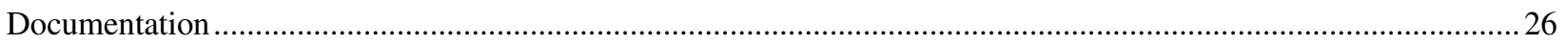

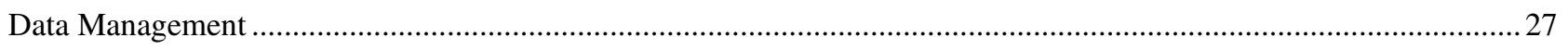

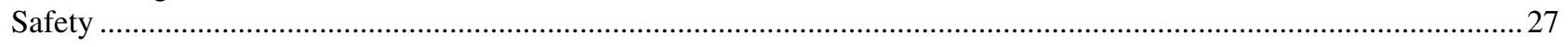

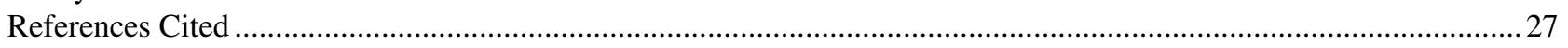

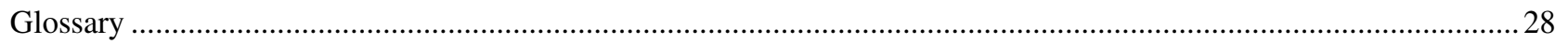

\section{Figures}

1a. Example of U.S. Geological Survey Sediment Laboratory Analysis Request (SLAR)

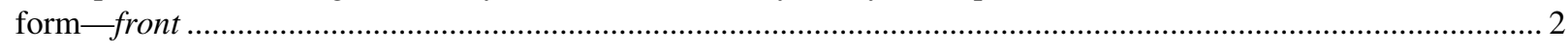

1b. Example of U.S. Geological Survey Sediment Laboratory Analysis Request (SLAR)

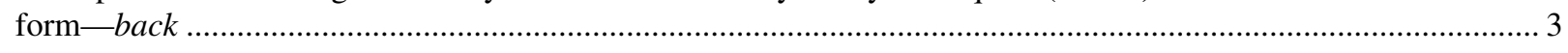

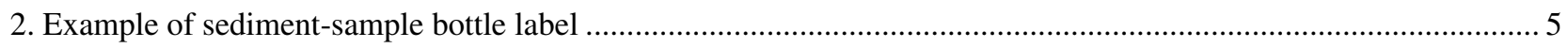




\section{Tables}

1. Standard methods of analysis and the recommended range of particle sizes for which the methods are applicable

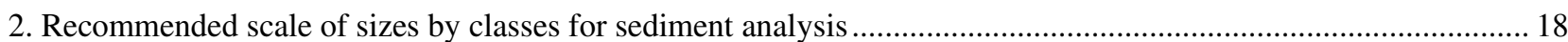

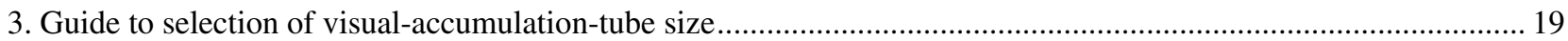

\section{Conversion Factors and Abbreviations}

\section{SI to Inch/Pound}

\begin{tabular}{|c|c|c|}
\hline Multiply & By & To obtain \\
\hline \multicolumn{3}{|c|}{ Length } \\
\hline centimeter $(\mathrm{cm})$ & 0.3937 & inch (in.) \\
\hline millimeter (mm) & 0.03937 & inch (in.) \\
\hline \multicolumn{3}{|c|}{ Volume } \\
\hline liter (L) & 33.82 & ounce, fluid (fl. oz) \\
\hline liter $(\mathrm{L})$ & 2.113 & pint (pt) \\
\hline liter (L) & 1.057 & quart (qt) \\
\hline milliliter (mL) & 0.03381 & ounce, fluid (fl. oz) \\
\hline \multicolumn{3}{|c|}{ Flow rate } \\
\hline liter per minute (L/min) & 0.2642 & gallon per minute (gal/min) \\
\hline \multicolumn{3}{|l|}{ Mass } \\
\hline $\operatorname{gram}(\mathrm{g})$ & 0.03527 & ounce, avoirdupois (oz) \\
\hline milligram (mg) & 35.27 & ounce, avoirdupois (oz) \\
\hline \multicolumn{3}{|c|}{ Density } \\
\hline gram per cubic centimeter $\left(\mathrm{g} / \mathrm{cm}^{3}\right)$ & 0.03613 & pound per cubic inch $\left(\mathrm{lb} / \mathrm{in}^{3}\right)$ \\
\hline
\end{tabular}


Temperature in degrees Celsius $\left({ }^{\circ} \mathrm{C}\right)$ may be converted to degrees Fahrenheit $\left({ }^{\circ} \mathrm{F}\right)$ as follows:

$$
{ }^{\circ} \mathrm{F}=\left(1.8 \times{ }^{\circ} \mathrm{C}\right)+32
$$

\section{Abbreviations}

Specific conductance is given in microsiemens per centimeter at 25 degrees Celsius $\left(\mu \mathrm{S} / \mathrm{cm}\right.$ at $\left.25^{\circ} \mathrm{C}\right)$.

Concentrations of chemical constituents in water are given in milligrams per liter (mg/L).

ppm - parts per million 


\title{
Quality-Assurance Plan for the Analysis of Fluvial Sediment by the U.S. Geological Survey Kentucky Water Science Center Sediment Laboratory
}

\author{
By Elizabeth A. Shreve and Aimee C. Downs
}

\begin{abstract}
This report describes laboratory procedures used by the U.S. Geological Survey Kentucky Water Science Center Sediment Laboratory for the processing and analysis of fluvial-sediment samples for concentration of sand and finer material. The report details the processing of a sediment sample through the laboratory from receiving the sediment sample, through the analytical process, to compiling results of the requested analysis. Procedures for preserving sample integrity, calibrating and maintaining of laboratory and field instruments and equipment, analyzing samples, internal quality assurance and quality control, and validity of the sediment-analysis results also are described. The report includes a list of references cited and a glossary of sediment and quality-assurance terms.
\end{abstract}

\section{Introduction}

This report describes a quality-assurance (QA) plan for the U.S. Geological Survey (USGS) Kentucky Water Science Center Sediment Laboratory in Louisville, Kentucky, to assure that standard procedures are being followed. This plan is based on quality-assurance and quality-control (QA/QC) guidelines described in Knott and others (1992) and Matthes and others (1992). Analytical methods described by Guy (1969) are followed and the methods documented.

The USGS Kentucky Water Science Center Sediment Laboratory is operated with a staff of one full-time hydrologic technician (certified laboratory chief), one permanent part-time employee, and additional part-time contract employees as required by changing work loads, under the direction of the Assistant Director, USGS Kentucky Water Science Center.

\section{Quality Assurance of Sample Management}

The reliability of analyses provided by the sediment laboratory is affected by sample documentation received with the sample, as much as the quality of the sample provided. Erroneous sample documentation, incorrect analytical procedures, or loss of sample integrity may result from samples received by the laboratory that have illegible or incomplete sample-label data, inadequate analysis instructions, or were damaged during shipment. 


\section{U.S. Geological Survey Sediment Laboratory Analysis Request (SLAR) Form}

Prior to sending samples to the laboratory, the originating office will complete the SLAR form (fig. 1a).

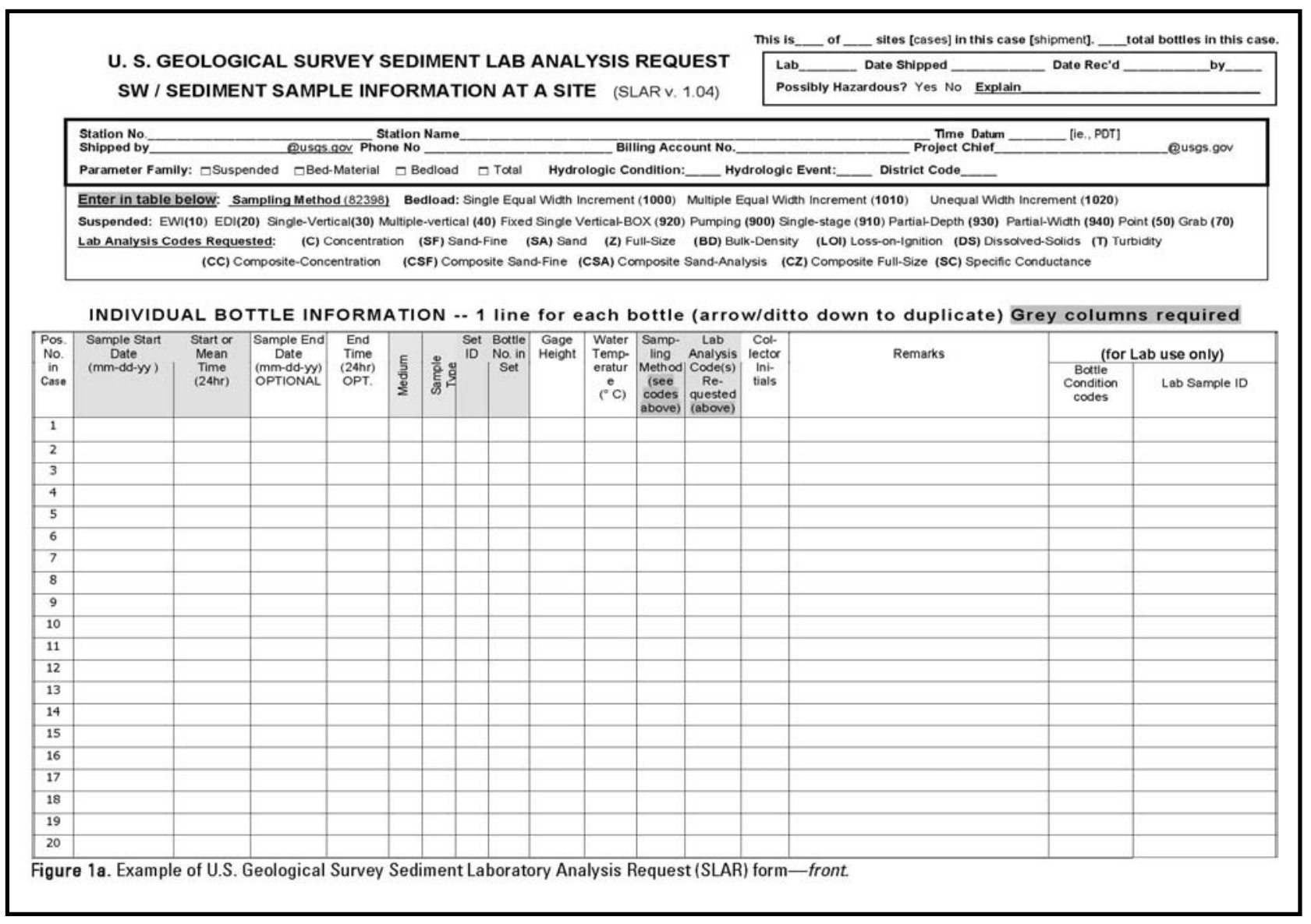

The most current version of the SLAR form is available online at http://water.usgs.gov/osw/techniques/sediment/sediment sample submittal form 104.doc, accessed June 13, 2005.

The completed form provides basic information required by laboratory personnel to correctly identify each sample and must be included with the corresponding shipping case of samples. Bottles are placed in shipping cases using the placement guides noted on the shipment-log form. Sample information is completed on the forms with bottle information corresponding to the sample number in the shipping case. If the shipping case contains samples from more than one stream location, a separate form must be completed for each location and included with the case. 
Suggestions for preparation and shipping of samples are as follows:

Use permanent markers for completion of the SLAR form. Include the account number (for billing purposes) in the designated space on the shipment-log form. Indicate any known or possible contaminants that might be present in the samples. Follow the placement guides on the back of the SLAR form (fig. 1b).

\section{U.S. GEOLOGICAL SURVEY SEDIMENT LAB ANALYSIS REQUEST BACK OF FORM - EXPLANATION (SLARV. 1.04)}

Lab: Sediment lab you are shipping sample to.

Shipped by: email id@usgs gov or phone will be used for login questions

Project Chief: email id@usgs.gov will be used for data transmittal information or questions.

District Code: NWQL "Users code" for NWIS host computer for data return to NWIS. Usually the same as the "State Postal code" (although some districts have a modified postal code for multiple NWIS hosts in a District, e.g. CA1 or FL1). Enter

NONE for non-USGS collectors

Parameter Family: Check the box for the appropriate type of sediment, each of which has its own group of NWIS Parameter codes for size fractions.

\section{NWIS codes:}

Medium: $9=$ Surface Water, $\mathrm{R}=$ Surface Water $\mathrm{QC}, \mathrm{H}=$ Bottom Material, $\mathrm{W}=$ Bottom Material $\mathrm{QC}$

1 = Suspended Sediment, $V=$ Suspended Sediment $Q C, B=$ Solids, $E=$ Core Material, $G=$ Soil, $J=$ Sludge, $3=$ Dry Deposition, 8 = Bulk Deposition, $U=$ Bulk Deposition $Q C, Q=$ Artificial $Q C$ (ie., equip. blank)

Sample Type: $9=$ Regular, $7=$ Replicate, $B=$ Other $Q A, H=$ Composite (time), $1=$ Spike, $2=$ Blank, 3 = Reference, $4=B$ lind Hydrologic Condition: $A=$ Not determined, $4=$ Stable, low stage, $5=$ Falling stage, $6=$ Stable, high stage, $7=$ Peak stage, $8=$ Rising stage, $9=$ Stable, normal stage,$X=$ Not applicable

Hydrologic Event: $A=$ Spring breakup, $B=$ Under ice cover, $C=$ Glacial lake outbreak, $D=$ Mudflow, $E=$ Tidal action, $\mathrm{F}=$ Fire, $\mathrm{H}=$ Dam break, $\mathrm{J}=$ Storm, $\mathrm{K}=$ Backwater, $1=$ Drought, $2=$ Spill, $3=$ Regulated flow, $4=$ Snowmelt, $5=$ Earthquake, $6=$ Hurricane, $7=$ Flood, $8=$ Volcanic action, $9=$ Routine sample, $X=$ Not applicable

Sampling Method: Enter one numeric NWIS fixed-value sampling method (NWIS Pcode 82398) per sample.

\section{NOTE THAT ONE LINE ON THE BOTTOM TABLE IS USED FOR EACH BOTTLE.}

Analysis Codes Requested - Enter code[s] for analyses requested in the column next to the remarks. Remarks - add remarks pertaining to the sample set or bottle.

\section{SHIPPING INSTRUCTIONS}

Follow placement guide for packing - Bottle \#1 information on the form should match Bottle \#1 in case.

$\checkmark$ Collection date (mm-dd-yy) and time (military) on the information sheet matches the bottle(s)

$\checkmark$ Please include both Shipper and Project Chief's email userids

$\checkmark$ Please make sure the containers are properly labeled and sealed

$\checkmark$ Enclose paperwork in a Ziploc type bag. Ship samples and accompanying paperwork in a well-padded and securelystrapped case.

\section{SHIPPING CASE BOTTLE}

\begin{tabular}{|c|c|c|c|}
\hline \multicolumn{4}{|c|}{ GUIDE "A" } \\
\hline 17 & 18 & 19 & 20 \\
\hline 13 & 14 & 15 & 16 \\
\hline 9 & 10 & 11 & 12 \\
\hline 5 & 6 & 7 & 8 \\
\hline 1 & 2 & 3 & 4 \\
\hline
\end{tabular}

\section{PLACEMENT GUIDE}

\begin{tabular}{|l|l|l|}
\hline \multicolumn{3}{|c|}{ GUIDE "B" } \\
\hline 10 & 11 & 12 \\
\hline 7 & 8 & 9 \\
\hline 4 & 5 & 6 \\
\hline 1 & 2 & 3 \\
\hline
\end{tabular}

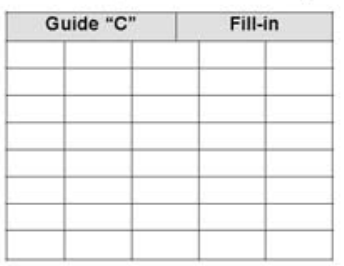

\section{(Lab use only)}

Bottle Condition Codes: use on front side, $2^{\text {nd }}$ to last column

NWL $=$ Water Line NOT Marked

WBL $=$ Water level below water line

NTP = Tape NOT Properly Applied

BRK $=$ Broken or Spilled

Sender will be notified by email when leakage or breakage is noted.

Figure 1b. Example of U.S. Geological Survey Sediment Laboratory Analysis Request (SLAR) form—back.

The most current version of the SLAR form is available online at

http://water.usgs.gov/osw/techniques/sediment/sediment sample submittal form back 104.doc, accessed June 13, 2005. Arrange samples in the shipping case in chronological order matching the bottle number information on the shipment-log form with the corresponding bottle number in the shipping case. Samples will be processed in the order in which they are placed in the case. 
Mark the water line of all bottles shipped in each case with a grease pencil to assist laboratory personnel in detecting if leakage or evaporation occurred at any point from the time the sample was collected until sample analysis.

Stream location names and downstream order numbers should be accurate and complete. Samples collected from more than one stream location may be shipped in the same case, but there must be a separate form for each sample location included in the case.

The sampling method, medium code, sample type, and lab analysis code must be provided for each sample, along with a sample start date and start time. Hydrologic condition and (or) hydrologic event may be provided on the SLAR header information.

If the bottles from a cross section or multi-bottle samples are to be composited for analysis or analyzed as discrete samples, document such on the form. If two or more cross sections are collected, indicate the type of analysis requested for each cross section. Mark the field-sample labels for a cross section as " 1 of 12,2 of $12, \ldots$ 12 of $12 . "$

Record the sample-shipping date. Laboratory personnel will record the date the samples were received and the condition of the samples upon arrival. The SLAR forms will be used in the lab to record applicable notes on the condition of the samples such as algae, underfilled or overfilled containers, foreign material present, leakage, or breakage.

Include the name and telephone number of the person responsible for the samples on the SLAR form to allow questions by laboratory personnel to be resolved in a timely manner.

Check to see that the number of samples shipped agrees with the total samples on the SLAR form.

\section{Null Qualifiers}

A sample in a damaged container is discarded unless it is determined the sample can be reconstituted. It may be possible to transfer the sample to a new container or to determine the amount of water/sediment loss. Pertinent comments regarding sample condition are recorded on the SLAR form, and customers are promptly notified of sample deficiencies. Customers are notified immediately if any samples were damaged during shipment. Samples are entered into the database using appropriate null qualifiers for a record of any samples that cannot be processed in the laboratory (received broken, insufficient water, etc.).

SLAR forms and sample cases are tagged with corresponding temporary case numbers upon arrival at the laboratory. The forms are sorted based on the analysis requirements of the samples. After the forms have been sorted by analysis type, water year, stream location, and chronological order, the cases of samples are sorted into analysis racks using the forms as guides. The cases of samples are renumbered for laboratory tracking purposes and stored in a cool, dark room until analysis.

\section{Sediment-Sample-Bottle Label}

The sediment-sample-bottle label (fig. 2) is completed at the time of sample collection. A permanent marker should be used to write on the label. Required label information supplied by the person collecting the sample is the water body (Stream), location, date, and time (use military time). Gage height (G.H.), measured water discharge (Qm.), water temperature (W.T.), specific conductance (Cond.), sample number (i.e., 1 of 12), and the initials of the collector (Party) also may be provided. The "Additional Data" section on the label may be used to record the collection station and method (box, point, EWI, EDI, grab, or other). 


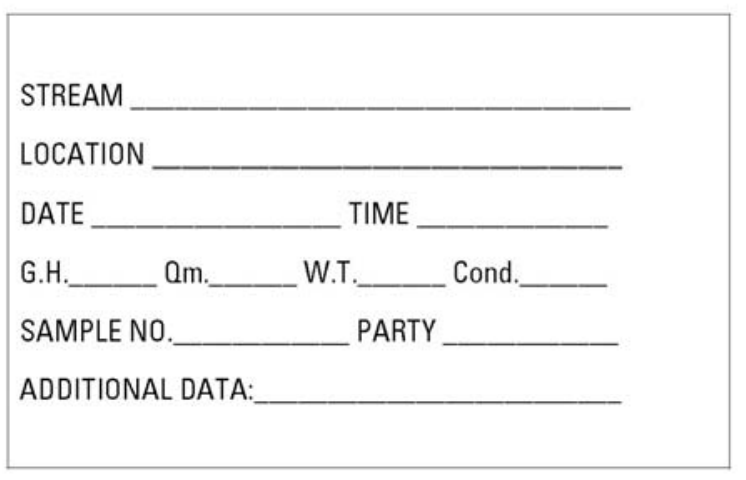

EXPLANATION

$\begin{array}{lll}\text { G.H. } & - & \text { Gage height } \\ \text { Qm. } & - & \text { Measured water discharge } \\ \text { W.T. } & - & \text { Water temperature } \\ \text { Cond. } & - & \text { Specific conductance }\end{array}$

Figure 2. Example of sediment-sample-bottle label.

Samples from an automatic sampler require the following information on the labels: station location, date the sample set begins, and sequence number 1 on the first bottle. If the bottles are kept together as a set, only the first and last bottles require both a sequence number and date. All other bottles require only a sequence number. A completed SLAR form, with bottle numbers and corresponding sequence numbers, must accompany these samples.

\section{Sample Shipment and Storage}

Under normal conditions, few problems are encountered when shipping samples during the warm-weather months. Extra care must be taken when shipping samples during cold weather because freezing may cause minerals to form a precipitate, glass bottles to fracture, or plastic bottles to split. Any of these conditions will compromise sample validity. Also, handling of fractured glass bottles by the carrier and laboratory personnel is a potential hazard. Avoid shipping samples when the air temperature is below freezing $\left(0^{\circ} \mathrm{C}\right)$.

The required shipping cases for glass pint or quart sediment-sample containers may be purchased through USGS One Stop Shopping at the following URL:

http://1stop.usgs.gov/ (accessed June 13, 2005).

These cases must be used if a shipment is mailed using the U.S. Postal Service. 3M Polyethylene Film Tape (or the equivalent) should be used on each bottle in the shipping case to secure plastic bottle lids to prevent loosening and leakage.

The USGS Kentucky Water Science Center Sediment Laboratory provides a written information sheet that summarizes laboratory policy for sample shipment and storage. Each customer is provided with instructions for shipment and storage of samples. Sample-storage instructions are displayed in the laboratory.

Proper storage of samples minimizes the potential for sample contamination or loss. Improper storage may result in algal growth, dirt, and grime accumulation on the exterior of the sample bottles, evaporation of water, spillage or breakage of samples, and loss of labels. The customer is advised of any problem.

If it is not possible to measure the weight of the samples when they are received, efforts are made to obtain the weights within 2 weeks of arrival to prevent error in analysis as a result of evaporation. Samples are stored in a cool, dark location to prevent algal growth.

The combined time for sample storage at the field and consolidation sites should not exceed 120 days. Bedmaterial or bedload samples are transported from the sediment station in bags, cartons, or other containers. 
Inspection and shipping procedures for these samples are similar to those for suspended-sediment samples (Knott and others, 1993).

\title{
Quality Assurance of Laboratory Equipment and Computer Software
}

\author{
A variety of specialized equipment is required for weighing, processing, and analyzing sediment samples. \\ Most equipment such as balances, ovens, specific-conductance meters, vacuum pumps, thermometers, and \\ calculators can be purchased from commercial sources. Decanting and filtering devices must be fabricated to best fit \\ the needs of the laboratory. \\ Reliable analytical results are achieved by use of calibrated equipment. The laboratory maintains the \\ calibration of its equipment by systematic checking against reference standards and routine-maintenance schedules. \\ Documentation is essential for support of the QA programs of the laboratory; therefore, all equipment used in the \\ laboratory has a logbook documenting calibration records.
}

\section{Balances}

Two types of balances are used in the USGS Kentucky Water Science Center Sediment Laboratory. The macro balance is used to weigh items ranging from 100 to 3,000 grams (g), with a precision of $+/-0.5 \mathrm{~g}$. The analytical balance is used to weigh items less than $100 \mathrm{~g}$, with a precision of $+/-0.0005 \mathrm{~g}$. Both balances are mounted on anti-vibration tables to maximize stability during use. The analytical balance has a protective hood over the weighing pan to minimize air-current disturbances. Both balances are fitted with RS232 connectors for electronic data transfer directly into a computer.

Balance calibration is checked prior to each weighing session. The macro balance is checked with at least two Class 1 weights, traceable to the National Bureau of Standards (Friedman and Erdmann, 1982), that bracket the range of expected weights of the samples. The macro balance is recalibrated if there is an error of more than +/- $0.5 \mathrm{~g}$. The analytical balance also is checked with at least two Class 1 traceable weights that bracket the expected weight to be measured. The analytical balance is recalibrated if the measured weight deviates more than $0.001 \mathrm{~g}$ from the standard weight. The balances are serviced by a technical representative if calibration does not bring them within required tolerances.

Balances are serviced and calibrated at least annually by a service representative using National Bureau of Standards traceable weights. All balance checks, calibrations, and professional servicing for each balance are recorded in dedicated instrument logbooks.

During computer entry, the analyst compares the weight displayed on the balance with the weight displayed on the computer terminal screen to confirm all entries. The empty balance is checked for a zero reading between each weighing with the balance being readjusted to zero after every 10 readings.

\section{Ovens}

A convection-type drying oven is used to dry the sediment contained in crucibles and evaporating dishes. The oven is required to maintain a temperature ranging from 85 to $103^{\circ} \mathrm{C},+/-2^{\circ} \mathrm{C}$. (See USGS OSW Technical Memorandum No. 99.04, dated January 25, 1999, Guidelines from the 1998 Sediment Laboratory Chiefs Workshop, online at http://water.usgs.gov/admin/memo/SW/sw99.04.html, accessed June 13, 2005.)

Oven temperatures are checked during each drying operation. The temperature of the oven thermometer is recorded in the logbook. There is a separate logbook for each oven. A Fluke 52 digital thermometer probe is connected to each oven. A Fisher Scientific National Institute of Standards and Technology (NIST) Traceable 2-channel probe digital thermometer also is connected to each oven as a second temperature check. The temperatures of the two thermometers are recorded in oven logbooks. If the Fluke thermometer differs by more than $2^{\circ} \mathrm{C}$ from the other, the batteries are checked and replaced, if needed. Next, the thermometers are checked and replaced, if needed. 


\section{Quality Assurance}

The 2-Channel thermometer was calibrated against the NIST traceable instrumentation. Calibration for the thermometer complies with international standards ISO 17025. The calibration thermometer may only be used within the period for which it was certified as NIST traceable. Once certification has expired, the NIST calibration thermometer must be replaced. The accuracy of the NIST thermometer is $+/-1^{\circ} \mathrm{C}$.

A Fisher Exact-temp certified chamber thermometer, calibrated to $103^{\circ} \mathrm{C}$, is magnetically mounted inside each oven. The Fluke and NIST calibration thermometer temperatures must maintain an accuracy of $+/-2^{\circ} \mathrm{C}$ of the certified chamber thermometer, or corrective actions are taken.

\section{Conductivity Meter}

The specific-conductance meter is used to measure the specific conductance of sediment samples. These specific conductance values assist in QA for samples collected at field sites and assure the purity of deionized water used in laboratory processes. The units of conductance are measured in microsiemens per centimeter at 25 degrees Celsius $\left(\mu \mathrm{S} / \mathrm{cm}\right.$ at $\left.25^{\circ} \mathrm{C}\right)$. Specific conductance of a water-sediment mixture is a useful indicator of the conductivity of a stream at the time a sample was collected.

Prior to measuring sample conductivity, meter linearity is checked with at least three standard solutions in the range of expected sample values. The meter is recalibrated if more than a 2-percent difference exists between the meter readings and the standard solutions. All calibrations are recorded in the specific-conductance meter logbook.

When the meter readings differ $+/-2$ percent or more from the standards, the probe should be cleaned or replaced following the manufacturer's suggested procedures. Sediment laboratory personnel participate in the nationwide USGS National Field Quality Assurance testing by the USGS laboratory in Ocala, Florida.

\section{Pipet-Method Equipment}

Pipet-method equipment is used to analyze material finer than $0.062 \mathrm{~mm}$ (millimeters). The pipet holds $\sim 25$ milliliters $(\mathrm{mL})$ of water-sediment mixture. Each pipet is rated for the volume of solution it will hold. Six withdrawals of deionized water are made with the pipet filled to the stopcock and emptied into pretared evaporating dishes. The weight of the dish and the deionized water are obtained as soon after the withdrawal as possible. The dish weight is subtracted from the weight of the water and dish; the high and low values are discarded. The weights of the water must agree to within 0.5 percent. The remaining weights are totaled and averaged. This average weight is converted to $\mathrm{mL}$ and used as the average volume of the particular pipet. Each time a pipet is replaced, a new average volume is determined. The pipet number, dish weights, and calculations are recorded in the pipet-method logbook.

A vacuum system is attached to one stem of the pipet. A deionized-water-rinsing system with air bulb is attached to the other stem to facilitate the emptying of the sample and flushing of the pipet between withdrawals.

Graduated sedimentation cylinders ranging in volume from 250 to $1,000 \mathrm{~mL}$ are used in the pipet analysis. The cylinders are either glass or plastic. The cylinders are checked for the correct volume by weight. The empty cylinder is weighed, filled with deionized water to the manufacture's volume mark, and reweighed. If the cylinder volume net weight differs by 0.5 percent from the indicated volume, the correct volume by weight is determined and a new water level mark is made on the cylinder. The process is repeated for each cylinder, and the results are recorded in the pipet-method logbook.

During the pipet analyses, the cylinders with the water-sediment mixture are placed in a constanttemperature water bath. The temperature is maintained by a heating element and water pump. The temperatures of the water bath and cylinders are recorded on the analysis worksheets for both the initial and ending temperatures. These temperatures are later entered into the computer software program for each sample analyzed.

A vacuum system attached to the pipet is used to make aliquot withdrawals during the analysis. The system is equipped with a vacuum gage and a bleeder-valve control that allows adjustment of the vacuum and regulation of the correct pipet withdrawal time. The calibrated rate of withdrawal fills the pipet in 12 seconds when the stem of 
the pipet is immersed to a depth of $15,10,5$, or 3 centimeters $(\mathrm{cm})$, depending on the required particle size depth. The withdrawal rate is checked before analyzing each set of pipet samples.

\section{Visual-Accumulation-Tube Equipment}

The visual-accumulation tube (VA tube) is used to analyze sand particle sizes from 0.062 to $2.0 \mathrm{~mm}$. The VA-tube equipment consists of a glass tube $120 \mathrm{~cm}$ in length. The diameters of the accumulation chambers in the 120 -cm tubes are 2.1,3.4, 5.0, and $7.0 \mathrm{~mm}$. A chart, calibrated for VA-tube analysis, is mounted on a circular drum. A viewing scope, photoelectric cell, and chart pen are moved upward by hand. The pen draws an analog curve on the calibrated chart during the analysis.

Before each set of analyses or when the tubes are changed, the tube, rubber connecting tube, and funnel section are dismounted, washed with detergent, and rinsed with deionized water to remove detergent residue. After reassembly, the top reference mark on the mounting board is aligned with the reference mark on the funnel, and the top-of-the-tube stopper is aligned with the bottom reference mark on the mounting board. After each analysis, the tube assemblies are rinsed thoroughly with deionized water. Chart-drum rotation is verified once a day each day the VA tube is used. The mechanism is cleaned and lubricated and timing marks are checked before each use. Timing verification results and any necessary corrective actions are recorded in the VA-tube logbook.

\section{Sieves}

Sieves are used in determining the particle-size distribution of sample material that is larger than $0.062 \mathrm{~mm}$. The sieves are inspected before each use for particle-clogged areas of the screen or tearing in the wire cloth. A magnifying glass is used for inspection, if needed. Sieves must retain a taut wire mesh without tears or clogging in order to maintain the integrity of the screen size (Tyler Industrial Products, 1976).

\section{Dry-Sieve Equipment}

Two sets of 8-inch sieves are maintained for determining particle sizes according to the standard USGS scale (Guy, 1969). A Rotap machine is used to agitate the sieves during dry-sieve analysis.

All sieves are cleaned with an ultrasonic cleaner if estimated to have more than 25 percent of the surface area clogged with material. Sieves that cannot be cleaned are replaced. Brass or nylon brushes are used for routine cleaning of sieves during dry-sieve analysis. One sample in 20 is reanalyzed, or the sample is split and analyzed for particle-size distribution. If the size-distribution differs by more than 3 percent in any size class, the sample is reanalyzed. Reanalyzed sample results and any necessary corrective actions are recorded in the sieve logbook.

Samples requiring reanalysis usually contain heavy organic material that breaks down under Rotap agitation. The size particles will continue to vary with further agitation. Other samples requiring reanalysis could be related to minor variations in techniques from one person to another. There also is the possibility that 100 percent of the sample was not recovered during the primary analysis.

\section{Decanting Equipment}

The decanting equipment consists of a J-shaped decanting nozzle attached to rubber tubing that is connected to a vacuum system. To avoid disturbing the sediment, a regulator has been added to the vacuum system and adjusted so the samples will decant at a rate not to exceed 1 to $1-1 / 2$ liters per minute (L/min). 


\section{Filtering Equipment}

The filtration-method analysis of sediment samples requires the use of filtering equipment. The equipment consists of crucible holders (with filter adapters and glass funnel stems), rubber tubing, shut-off valves, storage tank for collecting surplus water, and a vacuum device. Crucible holders are mounted on counters specifically designed for this purpose.

\section{Computer Software}

The information and data results for suspended-sediment samples for particle-size analyses are entered into the Sediment Laboratory Environmental Data System (SLEDS) software program. Documentation for the SLEDS software is available online at http://eris.wr.usgs.gov/SedLab/framework.html, accessed June 13, 2005.

The SLEDS software is used to record, calculate, and store data from various instruments. Data transcription errors are minimized by use of these automated programs, because electronic data transfer eliminates keypunch and inaccurate transcription errors.

The computer software is maintained by the USGS Kentucky Water Science Center computer section.

\section{Quality Assurance of Laboratory Apparatus and Standard Solutions}

A variety of apparatus and standard solutions are commonly used in the laboratory when analyzing samples. Various laboratory apparatus include desiccators, sample sieves, and crucibles. Standard solutions include deionized water and specific-conductance standards. Written cleaning procedures for sample containers, evaporating dishes, and crucibles are posted in the laboratory near the cleaning area. All laboratory personnel are trained in cleaning techniques for the various types of apparatus.

\section{Desiccators}

Desiccator cabinets are used to store crucibles and evaporating dishes after they are removed from the drying oven to prevent the samples from reabsorbing moisture from the air during cooling. Hygrometers mounted in the desiccator doors indicate the humidity level of each desiccator cabinet. Desiccant containing a color indicator that monitors moisture is placed in the lower portion of each desiccator cabinet. When the hygrometer reading exceeds the acceptable range or the desiccant color indicator has changed, the desiccant is removed from the desiccator and oven-dried overnight at 85 to $103^{\circ} \mathrm{C}$. Sample containers are assigned to a specific desiccator and are maintained in that desiccator throughout the processing sequence, because humidity levels vary slightly in each desiccator.

Desiccators are washed periodically with a laboratory detergent. The desiccant is dried and new desiccant or indicator is added as needed.

\section{Sample Bottles}

Sediment samples may be collected in many types of sample containers. The 1-pint glass milk bottles and 1-quart glass bottles are the most common types of bottles used in standard USGS depth-integrating and point samplers. Automatic samplers use plastic or glass containers of varying sizes and shapes.

Empty sample bottles are weighed on the macro balance at the USGS Kentucky Water Science Center Sediment Laboratory to obtain the tare weight of the sample bottles to the nearest $1 \mathrm{~g}$. This tare weight is then etched on the glass bottle or marked on plastic bottles with a permanent waterproof marker. Tare weights followed by an asterisk indicate the bottle weight includes the weight of the field label. 
When samples have been analyzed, the empty glass sample bottles are first rinsed with an 8-percent solution of hydrochloric acid (HCL) to remove any calcium build-up or clouding of the bottle. Rinsing is done under a chemical-fume hood in the sediment laboratory. Protective gloves, clothing, and goggles are worn when using acid to pre-clean sample bottles.

Glass bottles are washed next with tap water, a low-residue detergent, and a hand-held bottle brush. The low-residue detergent removes oil, grease, and other hard-to-remove material. A thorough rinse in tap water removes detergent and any remaining residue. The bottles are placed upside down on a bottle rack and air-dried overnight. The dried bottles are inspected for cleanliness, re-labeled, capped, and packed in shipping cases. If necessary, the washing procedure is repeated on bottles that were not thoroughly cleaned after the first washing. If chipped or cracked glass bottles are found during inspection, the bottles are discarded.

Plastic and nalgene bottles are more difficult to clean. Their shapes do not conform to the shape of the bottle brush, and the bottle brush could scratch the plastic allowing sediment to become trapped in etch marks during subsequent use. Residue inside the bottles is difficult to see because most plastic containers are opaque. If a residue build-up is evident, the bottle is rinsed with an 8-percent HCL solution, washed with laboratory detergent, and the interior is brushed manually. The bottle is thoroughly rinsed in tap water to remove detergent residue, and the drying procedure for glass sample bottles is followed. Plastic bottles are examined for cracks and interior scratches; defective bottles are discarded.

\section{Evaporating Dishes}

Evaporating dishes are made of Pyrex glass and are used to weigh sediment in samples requiring the evaporation analytical process. The dishes are washed manually using a nylon scrub pad or a brush, followed by a thorough rinse in tap water. Dishes not in use are stored in closed drawers, while dishes for analysis are oven-dried at $103^{\circ} \mathrm{C},+/-2^{\circ} \mathrm{C}$, and cooled in assigned desiccators prior to use. Tongs or cotton or nitrile gloves are used to handle the evaporating dishes or beakers. Dishes are weighed to the nearest $0.0001 \mathrm{~g}$ with the analytical balance to obtain their tare weights prior to analysis.

\section{Crucibles}

Coors porcelain crucibles are used in the USGS Kentucky Water Science Center Sediment Laboratory. The crucibles are fitted with a Whatman \#934-AH glass-fiber filter that allows for $1.5 \mu \mathrm{m}$ retention of suspended solids. The crucibles are used for samples estimated to have sand concentrations less than 10,000 parts per million (ppm) and clay concentrations less than $200 \mathrm{ppm}$. If the quantity of fine sediment is too great, the filter will become clogged and some liquid will be retained in the crucible.

Crucibles are prepared for use in analyses by washing them in warm water and a low-residue detergent with a nylon scrub pad to remove any deposit build-up. Crucibles are thoroughly rinsed with tap water, placed under vacuum, and seated with glass-fiber filters.

Filters are seated by placing a glass-fiber filter centered in the crucible and applying vacuum. Deionized water is filtered through the crucible. The deionized water aids in seating of the filter and helps remove loose glassfilter fibers. While the filter is under vacuum, it is checked for air escaping around its perimeter. If air is detected, the vacuum is turned off, the filter is adjusted and rewetted with deionized water, and the vacuum re-applied. The filter is replaced if it does not seat properly.

The crucibles with properly seated filters are placed in a Pyrex tray and oven-dried 3 hours to overnight at $103^{\circ} \mathrm{C},+/-2^{\circ} \mathrm{C}$ (Matthes and others, 1992). The crucibles are immediately placed in assigned desiccator cabinets to cool at least 3 hours before weighing. Each crucible, with filter, is weighed to the nearest $0.0001 \mathrm{~g}$ before use. Crucibles are assigned a specific desiccator cabinet to minimize humidity changes during the analysis procedures. Tongs or cotton or nitrile gloves are used by laboratory personnel when handling crucibles to avoid contaminating crucibles with moisture, dirt, or oil. A filter logbook of the lot numbers, dates received, and dates used is maintained to document filter usage in the event a certain production lot is found to be defective. 


\section{Deionized Water}

Deionized water is used in the laboratory to prevent the addition of dissolved solids when the sediment sample is rinsed into a crucible or evaporating dish or during wet-sieving. Deionized water is produced by passing tap water through a mixed cation-anion exchange resin. The deionized water system is furnished through a local company. The indicator light and meter level are observed daily to determine if the water is suitable for use. The company is notified when the indicator light goes out and tanks are exchanged promptly. The specific conductance of deionized water at $25^{\circ} \mathrm{C}$ must not exceed $10 \mu \mathrm{S} / \mathrm{cm}$ (Knott and others, 1992). Specific conductance of the deionized water is measured and the readings are recorded in a deionized water logbook when samples being entered into the computer require conductance readings.

Storage bottles for deionized water require periodic cleaning with deionized water and liquid bleach to remove organic build-up. A cleaning solution of about $250 \mathrm{~mL}$ of liquid bleach and $20 \mathrm{~L}$ of detergent water is added to the storage bottle. The storage bottle is agitated and allowed to soak for 5 minutes; this procedure is repeated at least three times. A brush is used to remove material that cannot be removed by agitating, and the bottle is rinsed with deionized water until there is no evidence of residue.

\section{Specific-Conductance Standard Solutions}

Specific-conductance standard solutions are obtained from the USGS National Water Quality Laboratory (NWQL), in Denver, Colorado. All standards are labeled with an expiration date and are discarded after that date. Specific-conductance standard solutions are stored in tightly capped containers to avoid contamination and evaporation. Solutions are discarded after calibration procedures.

\section{Quality Assurance of Analytical Procedures}

The USGS Kentucky Water Science Center Sediment Laboratory follows the methods described in Guy (1969) when analyzing fluvial-sediment samples for concentrations or sand-fine separations.

The standard scientific unit used for expressing sediment concentration in the laboratory is milligrams per liter $(\mathrm{mg} / \mathrm{L})$. The sediment concentration is calculated automatically by a computer program as follows: $\mathrm{mg} / \mathrm{L}=$ Concentration $(\mathrm{ppm})=$ Concentration

$$
\left[\frac{\text { Weight of sediment } x 10^{6}}{\text { Weight of water - sediment mixture }}\right]
$$

A linear conversion automatically takes place within the SLEDS software to report data results in $\mathrm{mg} / \mathrm{L}$ and, at higher limits, also in ppm.

\section{Concentrations}

The procedures followed by the USGS Kentucky Water Science Center sediment laboratory for concentration determination are listed below. These procedures focus on QC and include specifics not contained in Guy (1969).

Two ASTM D3977-97 (2002) methods used for the analysis of suspended-sediment concentrations are the filtration method (Test Method B) and the evaporation method (Test Method A).

The filtration method requires use of a crucible, a filter, and the vacuum system. The sample is poured into a crucible, and vacuum pressure is applied. After the water-sediment mixture is forced through the filter, the crucible is oven-dried, cooled, and weighed. The advantage of this method is that the dissolved solids present in the sample 
water will pass through the filter; therefore, mathematical adjustments for dissolved solids are not needed. A disadvantage to this method is that large quantities of sediment in the sample can clog the filter, which slows filtration.

The evaporation method is used when the concentration of the water-sediment mixture exceeds $10,000 \mathrm{mg} / \mathrm{L}$ of sediment that is mostly sand and $200 \mathrm{mg} / \mathrm{L}$ of sediment that is mostly clay (Guy, 1969). After washing the water-sediment mixture into the evaporation dish, the sample is dried and weighed. The primary disadvantage of the evaporation method is that a correction for dissolved solids may be required. A dissolved-solids correction needs to be applied when the concentration of dissolved-solids is greater than $200 \mathrm{mg} / \mathrm{L}$, and the concentration of sediment is less than $200 \mathrm{mg} / \mathrm{L}$ (Guy, 1969).

\section{Login of Samples for Concentration Analysis}

Upon receipt at the laboratory, samples and SLAR forms are examined for sample condition and requested analysis type. When the laboratory receives the samples, the samples are checked for damage during shipment, damage is noted on the form, and customers are notified if damage occurred. The forms are used by the laboratory to verify that all samples have been received.

The data-entry procedures described are used in conjunction with the Sediment Laboratory Environmental Data System (SLEDS), the INGRES-based sediment program supported by the Office of Surface Water (OSW) computer program. Documentation for this program is maintained at the Cascade Volcano Observatory Laboratory (CVO).

Use of the computer during data entry and processing eliminates errors that are common during manual processing of samples. Transcription errors are eliminated by electronic transfer of balance readings. The samples are logged-in chronologically, when possible. Login of a concentration sample consists of entering the station number and name for the sample; the sample field label information; measurement of laboratory specific conductance if requested by the customer; the bottle tare weight, and the gross weight of the bottle and watersediment mixture; and the selection of the method to be used for the analysis. The computer program stores the data in database tables. Login information is printed and compared with information on the SLAR forms. Mislabeled or missing samples are noted on the log forms. The customer is contacted if sample information cannot be resolved in the laboratory.

Five percent of the samples analyzed are QC sample blanks or field replicates. The laboratory chief is responsible for providing sample blanks, while field replicates are provided by the customer. Results of the sample blanks and field replicates provide quantitative information about computer-program performance, analytical efficiency, and sample-collection technique.

A login summary report is printed after the login portion of the analysis is complete. The worksheet is used by laboratory personnel during the remainder of the analysis for comparison with sample information and data. The worksheet is used to rebuild the data file if the computer malfunctions, and the data file is lost.

A listing of the station locations in a data file and the number of samples analyzed for each location are available as part of the computer-generated results. The laboratory retains a copy of this listing and records the inclusive dates of the analysis in a log of the samples analyzed.

\section{Data Entry of Concentration Analyses}

Login inputs sample information from the SLAR form and sediment-sample-bottle label. Procedures during Login include the following:

- $\quad$ Bottles are checked with corresponding bottle data on the SLAR form.

- Bottles are assigned a unique record number that will be kept throughout the analysis procedure. When a customer provides a unique sample number, that unique number will be recorded in the sample remarks when the sample is logged in. 
- Information from the sediment-sample-bottle label is checked against the information on the SLAR form, and the bottle tare weight is entered into the computer. If no tare weight is available, the sample is marked and a tare weight is determined after the bottle is washed and dried. The data file is then edited to reflect the correct tare weight for calculation purposes.

- Gross weights obtained from uncapped samples and specific conductance is entered into the computer.

- Sample net weight is automatically calculated by the computer program.

- Login summary data files are printed and reviewed by the laboratory technician before proceeding.

Sample bottles are moved to the filtration area to allow sediment to settle. Samples remain on the decanting table overnight before proceeding with the decanting process. Decanting is delayed if the samples appear cloudy after a 24-hour period, and an extended settling period may be considered. All samples must wait at least 2 weeks before decanting. Some samples may never be decanted if the native water remains turbid. Samples may be processed before the 2-week period, but the whole sample would be processed.

During analysis of data entry, the tare weights of crucibles and (or) evaporation dishes are entered into the computer. Procedures during analysis include the following:

- Crucibles and evaporating dishes are numbered with unique identification numbers for use in the laboratory.

- Crucibles are used in the filtration method.

- Evaporating dishes may be used with samples having net weights greater than $0.1 \mathrm{~g}$.

- Crucible or dish weight transfer is made by placing the container on the analytical balance. When the balance is stabilized, the letter "g" is displayed on the balance screen. By pressing the return key on the computer keyboard, the weight is electronically transferred into the data file.

- Crucible or dish weights and container identification numbers must be tared and available in SLEDS for all samples before proceeding to sample processing.

- A worksheet of the dish file report is printed for use during analysis of the samples.

- During final analysis of data entry, the containers plus dried sediment are weighed. Only the number of dishes or crucibles that can be weighed in less than 1-minute exposure time to the ambient temperature are removed from the desiccator. The desiccator is closed between each removal process. Samples are weighed to the nearest $0.0001 \mathrm{~g}$ on the analytical balance, and the gross weight is electronically transferred in the same method as the tare weight. Crucibles and dishes are transferred from the desiccator to the balance by using tongs or cotton or nitrile gloves.

\section{Quality-Control Measures for Data Entry of Concentrations}

- SLAR forms are compared with data entered into the computer to confirm sample documentation.

- The analytical balance is connected to the computer, and the data are transferred electronically. Each digital display is compared with the weight entry on the screen to assure validity of the weight. The 0.0 -g empty weight display is checked between each weighing.

- The weight displayed on the balance is compared with the weight shown on the computer screen.

- Tongs or cotton or nitrile gloves are used to handle any glassware.

- Desiccator door is tightly closed between weighings.

- Each crucible or dish is weighed within 1 minute of removal from the desiccator.

- Data worksheets of the concentration notes are reviewed, edited if needed, and initialed by the reviewer. A final print of notes is presented to the laboratory chief for final review. 


\section{Analysis of Samples for Concentration}

The analysis of samples for concentration requires supplies and equipment, the determination of sampling method (filtration or evaporation), calculation of dissolved-solids corrections, and QC measures. Equipment and methods are described in Guy (1969), with the exception of QC measures. The following list highlights the key components of each category for the analysis of samples for concentration.

\section{Supplies and Equipment}

- Coors porcelain crucibles

- Whatman \#934-AH glass-fiber crucible filters

- Crucible holders

- Pyrex evaporating dishes (100- and 200-mL capacity)

- Deionized water

- Vacuum system

- Analytical and macro balances

- Drying oven

- Decanting equipment

- Desiccator cabinets

- Computer and concentration software program

\section{Filtration Method}

Sample data on the worksheet are compared with data on the field-sample label and with the bottle tare value. Errors are recorded on the worksheet and corrected in the edit option of the concentration software program.

Most of the sediment-free water in the sample bottle is decanted using care not to disturb or remove sediment. A J-shaped tube and a vacuum system are used to suction the supernatant water from the top, away from the sediment. Care is taken not to tilt the bottle, which could disturb the sediment. The decanting rate should not exceed 1 to $1-1 / 2 \mathrm{~L} / \mathrm{min}$. The crucible is placed in the crucible holder, the filter wetted with deionized water, and suction applied to seat the filter. The crucible identification number is checked against the container identification number on the sample to ensure agreement. All sediment is washed from the sample container with deionized water into the appropriate crucible. Care is taken not to spill any of the sample during the transfer. Crucibles are placed in a convection oven and dried at $103^{\circ} \mathrm{C},+/-2^{\circ} \mathrm{C}$, for a minimum of 3 hours or overnight. Crucibles are immediately placed into a desiccator to cool for at least 3 hours or overnight.

\section{Evaporation Method}

The evaporation method is used if it is evident the sample contains a large amount of sediment that would be difficult to filter in a crucible. The water-sediment mixture is poured into the evaporating dish, and the sample is dried and weighed. If required, a dissolved-solids sample is collected and analyzed prior to the evaporation analysis. Evaporating dishes are aligned sequentially on the countertop. Sample data on the worksheet are compared with data on the field-sample label and with the bottle tare value. Errors are recorded on the worksheet and corrected using the edit option of the concentration program. The dish-identification number is checked against the containeridentification number on the sample to ensure agreement. All sediment is washed from the bottle into the dish using deionized water. A dish of sufficient volume is used to avoid spillage when transferring the dish to the convection oven. Evaporating dishes are placed in the oven. To avoid any loss of sediment from boiling, the dishes are dried at 85 to $95^{\circ} \mathrm{C}$ until all visible water has evaporated. With the removal of all visible water, samples are dried for an 
additional 3 hours at $103^{\circ} \mathrm{C},+/-2^{\circ} \mathrm{C}$, or overnight. Containers are then cooled in a desiccator for a minimum of 3 hours or overnight.

\section{Dissolved-Solids Correction Calculation}

The tare weight of a $100 \mathrm{~mL}$ evaporating dish is measured and recorded.

Before decanting, $25 \mathrm{~mL}$ of sediment-free native water is removed from the sample, by use of a pipet, and placed in the evaporating dish.

The evaporating dish is dried at 85 to $95^{\circ} \mathrm{C}$ until visible water has evaporated. The oven temperature is raised to $103^{\circ} \mathrm{C},+/-2^{\circ} \mathrm{C}$, for 1 hour to complete the drying process.

The dish is placed in a desiccator cabinet to cool. (Note: Evaporation dishes used to calculate dissolvedsolids corrections are never placed in desiccators containing environmental samples.)

The gross weight of the dish and solid residue are calculated and recorded.

The net weight of the residue is calculated and recorded.

The dissolved-solids correction (C) is computed as follows:

$$
\frac{C=\text { Net weight of residue } \times \text { sample volume (after decanting) }}{25 \mathrm{~mL} \text { (pipet volume) }}
$$

The net weight is measured to the nearest $0.0001 \mathrm{~g}$, and the volume of sample (after decanting) is estimated to the nearest $1 \mathrm{~mL}$. The dissolved-solids correction is then subtracted from the sediment net weight before calculating the concentration of the sample.

\section{Quality-Control Measures}

- Time to dry and desiccate crucibles is replicated when drying and desiccating samples.

- Crucibles and evaporating dishes are assigned to a specific desiccator throughout the analyses to compensate for variations in humidity.

- Label information, bottle tare weight, and crucible identification are compared with corresponding data on the worksheet for accuracy.

- Precalculated system-check, blank, and field replicate samples are immediately reviewed to verify analytical results.

\section{Sand/Fine Separations}

Sand/fine separations are used to determine sample concentration and the amount of material that is less than or greater than sand size. The term fine fraction refers to particles that pass through a 0.062-mm mesh sieve and sand fraction refers to particles large enough to be retained on a sieve.

\section{Data Entry for Sand/Fine Analyses}

The SLEDS software program is used to store and compute the data and maintain a record of analytical status of samples. 


\section{Quality-Control Measures for Data Entry of Sand/Fine Analyses}

- The SLAR form is compared with sample data entered into the computer to confirm sample documentation.

- The analytical balance is connected to the computer; the sample gross weights and the evaporating dish and crucible tare and gross weights are transferred electronically. The $0.0 \mathrm{~g}$ empty weight is checked between each weighing.

- The weight displayed on the balance is compared with the weight shown on the computer screen.

- Tongs or cotton or nitrile gloves are used when handling glassware.

- Desiccator door is tightly closed between weighings of evaporating dishes or crucibles.

- Each crucible or dish is weighed within 1 minute of removal from the desiccator.

\section{Analysis of Samples for Sand/Fine Separation}

The analysis of samples for sand/fine separation requires supplies and equipment, wet-sieve processing calculation of dissolved-solids correction, and QC measures. SLEDS is used to store information and compute results for concentration and the percentage of sediment finer than $0.062 \mathrm{~mm}$. User documentation for this program is kept on file at CVO.

\section{Supplies and Equipment}

- A 0.062-mm mesh sieve

- Coors porcelain crucibles

- Whatman \#934-AH glass-fiber crucible filters

- Crucible holders

- Pyrex evaporating dishes (100- and 200-mL capacity)

- Deionized water

- Vacuum system

- Analytical and macro balances

- Drying oven

- Decanting equipment

- Desiccator cabinets

- Computer and a particle-size computer program

\section{Wet-Sieve Processing}

ASTM D3977-97 (2002) Method C, wet-sieving filtration, is used to separate sand and coarser material from finer material.

Thoroughly wet the surface of the sieve and place in a Pyrex evaporating dish.

The sample is washed onto the sieve with deionized water. The screen is rinsed with a gentle stream of water (gravity flow) to wash the particles through and into the assigned dish. A hand oscillator is used to help with the separation process.

The sample may require more than one rinse. The screen stays immersed in deionized water during the rinsing procedure. Rinse until no visible fines pass through the screen. 
The sieve is then rinsed with deionized water on the sides and underneath to remove any fine particles that may have adhered to the sieve.

The sample fractions are dried according to the methods listed in the "Analysis of Samples for Concentration" section.

The gross weights of sample fractions are obtained electronically by use of the analytical balance and the SLEDS computer program.

\section{Dissolved-Solids Correction Calculation}

If a sample is dried in evaporation dishes, a dissolved-solids correction may be needed. This correction should be subtracted from only the fine fraction since the sand fraction is rinsed entirely with deionized water.

\section{Quality-Control Measures}

Sieve screens are checked with a magnifying glass before and after each use and cleaned, repaired, or replaced, as needed.

Crucibles or evaporating dishes, with unique identification numbers, are assigned to each sample to obtain sand weights. The identification number of the crucible or dish is written on the worksheet. Crucibles are assigned to each sample for use in obtaining fine weights; more than one crucible may be necessary. The crucible identification numbers are written on the worksheet.

\section{Login of Samples for Particle-Size Analysis}

The login process is used to account for the sample in the laboratory. The computer is used to store the data and maintain a record of the analytical status of the sample. The computer program SLEDS, developed at the CVO, is used by the USGS Kentucky Water Science Center Sediment Laboratory, for sample login, data entry, and data storage and retrieval.

When samples are received by the laboratory, they are recorded in the receiving logbook with date received, number of bottles and samples, and analysis required.

\section{Computer Entry}

The computer entry of the particle-size sample takes place soon after arrival typically following a 2-week settling period. The field-data entry and the weighing procedure are similar to the concentration program. The entered data and SLAR data are compared; data files are printed and used throughout the analysis processes.

\section{Particle-Size Analysis}

Several methods of analyses can be used to determine the broad range of particle sizes (0.001 to $128 \mathrm{~mm})$ encountered in suspended-sediment and bed-material samples as shown in table 1 (from Knott and others, 1993). 
Table 1. Standard methods of analysis and the recommended range of particle sizes for which the methods are applicable [from Knott and others, 1993].

$[--$, not applicable; $<$, less than; >, greater than $]$

\begin{tabular}{llc}
\hline Determination & Method of analysis & $\begin{array}{l}\text { Recommended } \\
\text { particle-size range } \\
\text { (millimeters) }\end{array}$ \\
\hline Concentration & Filtration & $<4.0$ \\
Particle-size & Evaporation & $<4.0$ \\
& Sieve & $0.062-32$ \\
Specific conductance & Visual-accumulation tube & $0.062-2.0$ \\
Turbidity & Pipet & $0.002-0.062$ \\
Specific gravity & Conductivity meter & -- \\
Specific weight & Nephelometer & $<0.062$ \\
\hline
\end{tabular}

The commonly used particle-size methods in the USGS Kentucky Water Science Center Sediment Laboratory are sieve, VA tube, and pipet. This section outlines the bench-level protocols used in these methods of particle-size analyses. Table 2 (modified from Guy, 1969) references the various size classifications that can be analyzed in the USGS Kentucky Water Science Center Sediment Laboratory.

Table 2. Recommended scale of sizes by classes for sediment analysis [from Guy, 1969].

[--, not applicable]

\section{Manufacturer \\ sieve \\ number $^{1}$}

U.S. standard sieve number ${ }^{2}$
Class name

Cobbles

3
3

$\begin{array}{rr}3 & \\ 3 & 3 \\ 3 & 3 \\ & 3 \\ 2.5 & 3 \\ 5 & 5 \\ & \\ & \\ 9 & 10 \\ 16 & 18 \\ 32 & 35 \\ 60 & 60 \\ 115 & 120\end{array}$

Large cobbles

Small cobbles

Gravel

Very coarse

Coarse

Medium

Fine

Very fine

Sand

Very coarse

Coarse

Medium

Fine

Very fine
256-128

128-64

64-32

32-16

16-8.0

8.0-4.0

4.0-2.0

2.0-1.0

1.0-0.50

$0.50-0.25$

0.25-0.125

1.125-0.062 
Table 2. Recommended scale of sizes by classes for sediment analysis [from Guy, 1969].

[--, not applicable]

\begin{tabular}{|c|c|c|c|}
\hline $\begin{array}{l}\text { Manufacturer } \\
\text { sieve } \\
\text { number' }\end{array}$ & $\begin{array}{l}\text { U.S. standard } \\
\text { sieve number }\end{array}$ & Class name & Metric units \\
\hline \multicolumn{4}{|c|}{ Silt } \\
\hline 250 & 230 & Coarse & $0.062-0.031$ \\
\hline-- & -- & Medium & $0.031-0.016$ \\
\hline-- & -- & Fine & $0.016-0.008$ \\
\hline-- & -- & Very fine & $0.008-0.004$ \\
\hline \multicolumn{4}{|c|}{ Clay } \\
\hline-- & -- & Coarse & $0.004-0.0020$ \\
\hline-- & -- & Medium & $0.0020-0.0010$ \\
\hline-- & -- & Fine & $0.0010-0.0005$ \\
\hline-- & -- & Very fine & $0.0005-0.00024$ \\
\hline
\end{tabular}

${ }^{1}$ Meets ASTM E-11 specifications.

${ }^{2}$ For maximum size of the given class.

${ }^{3}$ Sieve openings are marked in inches and millimeters.

Most samples will require some type of pre-weighed container. Evaporating dishes, crucibles, and beakers that will be used during the sample analyses are preweighed before each use using a software routine TARE. The program prompts for the entry of the container identification, and then for the tare weight of the container on the balance. The weights are stored in the computer, which the SLEDS program can access later during data entry. The number and types of containers that will be used are estimated. The containers may be tared and placed in a desiccator until used. When a container is used, the sample SLEDS identification number is recorded on the worksheet. Data entry for a sample does not take place until analysis is complete.

\section{Dry-Sieve Method}

The dry-sieve method of analysis is used for sand and gravel samples weighing from 50 to $400 \mathrm{~g}$. The method, as described, closely follows the recommendations of Guy (1969) and Tyler Industrial Products (1976). The criteria for sieves and their testing were established by the American Society for Testing and Materials (1970).

\section{Equipment Required}

- Nest of sieves covering the size range of material

- Rotap shaker

- Computer

- Macro balance

\section{Procedure}

Separate the sand and gravel from the silt-clay fraction by wet sieving using deionized water if a pipet analysis of the fine material is required.

Air or oven dry the sand and gravel at $80^{\circ} \mathrm{C}$. 
Weigh the sample. Split the sample if the weight is more than $400 \mathrm{~g}$ and weigh split sample for analysis. Retain 5 percent of the split samples as replicated.

Shake the sample for 20 minutes in a Rotap.

Enter the size-fraction weights retained on each sieve into the computer using the SLEDS program. A lab number for the sample was created during the sample login. The lab number is selected from the program menu. The material retained on each sieve is weighed on the balance, and the computer program transfers the weight measurements electronically to the data file. After weighing the material on the sieves, the program computes the final results of the analysis. Compare the difference in weights of the total sample measured and determine sample loss or gain during the analysis.

\section{Quality-Control Measures}

Re-analyze a sample if there is more than a 3-percent difference between initial weight and final weight.

Spot check the analytical procedures and correct if a deficiency is observed.

Reanalyze 1 sample in 20 or the sample-split fraction for QC. Reanalyze the sample if there is more than a 5 -percent difference in any size class. The results for all size classes are compared.

\section{Visual-Accumulation-Tube Method}

The VA tube is used for the analysis of sand sizes. The procedure described closely follows Guy (1969) and the Inter-Agency Committee on Water Resources (1958).

\section{Equipment Required}

- VA tube (see table 3 (from Guy, 1969))

- 600 or $1,000 \mathrm{~mL}$ beaker

- Sieves of 0.053-, 1.0-, and 2.0-mm mesh

- Evaporating dish

- Computer

- Analytical balance

Table 3. Guide to selection of visual-accumulation-tube size [from Guy, 1969].

[g, gram; mL, milliliter; mm, millimeter; cm, centimeter; --, not applicable]

\begin{tabular}{|c|c|c|c|c|c|}
\hline \multicolumn{2}{|c|}{$\begin{array}{c}\text { Quantity } \\
\text { of sample }\end{array}$} & \multicolumn{2}{|c|}{$\begin{array}{c}\text { Maximum } \\
\text { particle size }\end{array}$} & \multicolumn{2}{|c|}{$\begin{array}{c}\begin{array}{c}\text { Sedimentation } \\
\text { tube }\end{array} \\
\end{array}$} \\
\hline $\begin{array}{l}\text { Dry } \\
\text { weight } \\
\text { (g) }\end{array}$ & $\begin{array}{l}\text { Volume } \\
\text { of sand } \\
(\mathrm{mL})\end{array}$ & $\begin{array}{l}\text { Fall } \\
\text { diameter } \\
(\mathrm{mm})\end{array}$ & $\begin{array}{l}\text { Sieve } \\
\text { diameter } \\
(\mathrm{mm})\end{array}$ & $\begin{array}{l}\text { Length } \\
\text { (cm) }\end{array}$ & $\begin{array}{l}\text { Diameter } \\
\text { (mm) }\end{array}$ \\
\hline $0.05-0.8$ & $0.03-0.5$ & 0.25 & 0.25 & 120 & 2.1 \\
\hline $0.4-2.0$ & $0.2-1.2$ & 0.35 & 0.40 & 120 & 3.4 \\
\hline $0.8-4.0$ & $0.5-2.4$ & 0.50 & 0.60 & 120 & 5.0 \\
\hline $1.6-6.0$ & $1.0-4.0$ & 0.70 & 1.00 & 120 & 7.0 \\
\hline $5.0-15.0$ & $3.0-9.0$ & -- & 2.00 & 180 & 10.0 \\
\hline
\end{tabular}




\section{Sample Preparation}

The initial preparation of the sample required wet sieving and separation of material using a 0.053-mm sieve. The 0.062-mm size class will be determined by the VA-tube method. Depending upon the quantity and the size of the particles in the sample, the sample is split until $7 \mathrm{~g}$ or less of sand are obtained. Sediment coarser than these sizes is analyzed using the sieve methods.

Store the sand fraction for the VA-tube method in an evaporating dish. Add 40 to $50 \mathrm{~mL}$ of deionized water to cover the sample. Add $10 \mathrm{~mL}$ of hydrogen peroxide to remove organic material (Guy, 1969). After the organic matter has been removed, store the sample in a covered dish with sufficient water to keep the sample saturated.

\section{Tube Selection}

Tube selection is made easier if samples are sorted visually in ascending or descending order as to the quantity of sand in the sample.

After selecting the tube, dismantle tube components, wash with laboratory detergent, and rinse thoroughly with deionized water.

\section{Reassemble Components}

- $\quad$ Align top and bottom reference marks with permanent wall alignment marks.

- $\quad$ Open the upper valve of the VA tube.

- $\quad$ Fit the rubber stop plug in the bottom of the tube.

- $\quad$ Fill the tube with deionized water to just above the upper valve.

- $\quad$ Check tube for foreign material or retained sand.

- Measure water temperature in the tube.

- Turn on the light-control switch.

\section{Placing Chart on Drum}

- Push the drum-release lever down to rotate the drum until the paper-holding brackets face forward.

- $\quad$ Place the chart on the drum, secure brackets, rotate drum, and secure chart in brackets. Rotate drum and check that the chart is against the lower lip of the drum.

- Lower the telescope hairline to the top of the plug.

- $\quad$ Set the pen slightly above the chart baseline.

- Rotate the drum to establish a new baseline.

- $\quad$ Return the pen to $1 / 8$ in. to the right of the zero time line.

- Turn on the forward switch to bring the pen exactly on the zero time line.

- $\quad$ Recheck the telescope hairline (top of plug alignment).

- $\quad$ Close the upper valve.

\section{Analysis Procedure}

- Compare VA dish identification on worksheet with VA dish identification and unique number on VA graph. 
- Rinse sample into tube with deionized water and fill tube with deionized water to the reference line on top funnel.

- Turn on the tapper switch.

- Mix the sample vigorously with the mixing rod until the sample is well dispersed and then open the upper valve.

- The most critical time during the tracking of the sample is when the coarser particles begin to accumulate, or during the first 30 seconds that the particles fall.

- When the pen reaches the water temperature line on the chart in the $0.625-\mathrm{mm}$ range that corresponds with the temperature of the water in the tube, turn off the forward switch, immediately close the upper valve, rotate the drum to draw a top reference line at the height of the accumulated sediment, move the eyepiece upward, remove the bottom plug, and remove the accumulated sands.

- Drain the tube completely, rinse the remaining residue in the tube into an appropriately sized beaker, and let the residue settle. This residue will be returned to the fraction that is finer than $0.053 \mathrm{~mm}$ for further analysis or it will be dried and weighed. This weight is added to the non-analyzed part of the sample that is finer than $0.053 \mathrm{~mm}$.

\section{Completing the Analysis}

Place the evaporating dish in the oven. Dry evaporating dish at $80^{\circ} \mathrm{C}$ until all visible water is removed, then dry for an additional hour at $103^{\circ} \mathrm{C}$.

Weigh the VA-sample fraction using an analytical balance and the "VA Dish Entry" option of the computer program.

\section{Quality-Control Measures}

Reanalyze one sample each day the VA-tube analyses are processed. If the analysis varies by 5 percent or more in any size class, the sample is reanalyzed. If agreement is not within 5 percent for any size class, the deficiency is corrected and recorded in the VA-tube logbook.

Drain the tube and rinse thoroughly between each analysis.

Check alignment of reference marks each day the tube is used.

Time synchronize motors each day the VA-tube is used and record the results in the VA-tube logbook.

\section{Pipet Method}

Pipet analysis is used to determine the particle sizes of material ranging from 0.002 to $0.062 \mathrm{~mm}$. The pipet method is used for the particle-size analysis of both suspended-sediment and bed-material samples. The suspendedsediment sample requires the determination of the sample concentration in addition to any particle-size analysis. To determine the concentration of the sample, the total weight of the water-sediment mixture is determined before any other analytical processing. This takes place during the login of the sample, and the weight is stored in the data file by the computer program.

If colloidal material or glacial flour is present, the specific conductance of the supernatant water is measured, and a dissolved-solids correction in $\mathrm{mg} / \mathrm{L}$ is determined. One-hundred $\mathrm{mL}$ of the supernatant water are decanted and dried. A dissolved-solids correction in $\mathrm{mg} / \mathrm{L}$ is determined for the decanted supernatant. If the results show that colloidal or glacial material is the cause of the dissolved solids in the supernatant water, a correction factor is computed to be applied to the material finer than $0.002 \mathrm{~mm}$. The pipet-withdrawal schedule and the method procedure closely follow Guy (1969). 


\section{Equipment Required}

- A pipet rack with a constant-temperature water bath

- A pipet with a marked rated volume or computed volume

- A vacuum system

- A deionized-water supply

- A malt mixer and soil-dispersion cups

- A stopwatch or a timer clock with sweeping second hand

- Evaporating dishes (one for each required withdrawal)

- Sedimentation cylinders of various volumes from 250 to $1,000 \mathrm{~mL}$

\section{Preparation for Analysis}

Using the wet-sieve method, the sample is sieved with a $0.053-\mathrm{mm}$ mesh sieve. If sufficient material is present, the particle size of the sand is determined using the VA-tube method.

If the quantity of sand is insufficient for VA-tube analysis, the sample is wet sieved with a $0.062-\mathrm{mm}$ mesh sieve. The material larger than $0.062 \mathrm{~mm}$ is retained on the sieve, rinsed into an evaporating dish, and is oven dried at $80^{\circ} \mathrm{C}$ until all visible water is removed, and then dried for an additional hour at $103^{\circ} \mathrm{C}$.

The sedimentation cylinder should contain a concentration of sediment from 2,000 to 5,000 mg/L (Guy, 1969). Concentrations as small as $1,000 \mathrm{mg} / \mathrm{L}$ are acceptable at the request of the customer. The material that passes through the sieve is placed in a $1,000 \mathrm{~mL}$ or smaller graduated beaker. The sample is diluted with deionized water. The volume of water in the beaker is noted, and the beaker is placed on a magnetic stirrer for 5 minutes after which a pipet withdrawal is made. This aliquot is used to determine the optimum cylinder volume for the analysis. The aliquot is dried, cooled, and then weighed on the analytical balance. The weight is stored in the data file by the computer program. A list of the sample volumes and corresponding concentrations in $\mathrm{mg} / \mathrm{L}$ is displayed on the computer screen. The optimum-size cylinder for the sample is selected from the list.

The sample settles for 10 to 14 days or until the supernatant water is clear. The sample then is ready for analysis.

The supernatant water is siphoned off the sample, taking care not to disturb the settled sediment.

The dispersing agent is prepared as described in Guy (1969). It is added to the sample at a ratio of $1 \mathrm{~mL}$ agent per $100 \mathrm{~mL}$ of sample.

The supply of dispersant is kept in an amber bottle or stored in a closed dark cabinet.

The dispersant is discarded if it becomes cloudy.

The dispersant $\mathrm{pH}$ should range from 9.0 to 9.5 . If the $\mathrm{pH}$ is lower than 9.0, the dispersant is discarded.

The soil-dispersion cup is placed on the mixer and stirred for 5 minutes.

The sample is rinsed into the sedimentation cylinder and placed in the water-bath pipet rack.

Glassware for the analysis has been weighed using the balance and the pipet-tare option of the computer program. The weighed glassware is placed with the appropriate sample on the pipet rack. The glassware identification is checked with that recorded on the worksheet.

The first two withdrawals from a cylinder are used to determine the concentration of sediment in the cylinder. The sample in the first cylinder is stirred for 1 minute using a hand stirrer. A pipet withdrawal at a $15-\mathrm{cm}$ immersion depth is made immediately after stirring. The withdrawn aliquot is rinsed from the pipet into the first dish. The first cylinder is again stirred for 1 minute, and pipet withdrawal is made at $15 \mathrm{~cm}$. The pipet aliquot is rinsed into the second dish. This process of obtaining the concentration withdrawals is continued for the remaining cylinders. 
A pipet-withdrawal schedule showing the withdrawal times to determine standard USGS particle-size classes for material with a specific gravity of 2.65 grams per cubic centimeter $\left(\mathrm{gm} / \mathrm{cm}^{3}\right)$ is shown in Guy (1969). The times of the scheduled withdrawals are based on the temperature of the sample in the cylinder, specific gravity of the material, withdrawal depth of the pipet, and the particle size to be determined.

The temperatures of the samples in the cylinders are measured. The temperature is used to select the first withdrawal time and depth from the pipet-withdrawal schedule for the binning size class. The first sample is stirred with the hand stirrer for 1 minute, and a stopwatch is started to time the analysis for the pipet withdrawals. After 1 minute, the second cylinder is stirred. Each cylinder is sequentially stirred at 2-minute intervals remembering to start the stopwatch at the end of the 1-minute stirring cycle. Once the stopwatch is started, the time is continuous.

The withdrawal time on the schedule is the mean time of withdrawal. For example, if it takes 12 seconds to fill the pipet, the schedule shows that to make a withdrawal for the $16-\mu \mathrm{m}$ size at a temperature of $28^{\circ} \mathrm{C}$, the pipet is immersed to a depth of $10 \mathrm{~cm}$, and the time for the withdrawal is 6 minutes and 22 seconds; however, the actual time of beginning the withdrawal would be 6 minutes and 16 seconds.

The procedure is continued until all withdrawals are made. The samples are oven-dried at $80^{\circ} \mathrm{C}$ until all visible water is removed, then dried for an additional hour at $103^{\circ} \mathrm{C}$. The dishes are weighed using the analytical balance and the appropriate computer program. A final computer printout of the analysis can be obtained at this time.

\section{Computations}

The procedure for determining the concentration of sediment is to first subtract the dispersing-agent correction factor from each dish.

The dispersing-agent correction factor is determined by setting up two $500-\mathrm{mL}$ graduated cylinders filled to $500 \mathrm{~mL}$ with deionized water and adding $5 \mathrm{~mL}$ of dispersing agent to each cylinder. Four pipet withdrawals are made from each cylinder and retained in pretared evaporating dishes. The dishes are oven-dried, cooled, and then weighed on the analytical balance. The high and low weights are not used. The remaining weights are averaged for the dispersing-agent correction factor. The correction factor is recomputed if the pipet or the dispersing-agent supply is replaced.

In most pipet analyses the first two dish withdrawals are used to determine the concentration of sediment in the sedimentation cylinder. These withdrawals are made from a dispersed system and should be representative of the concentration of sediment in the sedimentation cylinder. For example, the weight of the material in dish 1 is $0.01014 \mathrm{~g}$, in dish 2 is $0.01008 \mathrm{~g}$, and the computed dispersing-agent correction is 0.0106 . The net weight of the sediment for dish 1 is $0.0908 \mathrm{~g}$ and for dish 2 is $0.0902 \mathrm{~g}$. The mean weight of the sediment for dishes 1 and 2 is $0.0905 \mathrm{~g}$. The relation between the volume of the pipet and the sedimentation cylinder is called the pipet-volume factor. The pipet-volume factor is determined by dividing the volume of the sedimentation cylinder by the volume of the pipet. The pipet-volume factor using a $500-\mathrm{mL}$ sedimentation cylinder and a $25-\mathrm{mL}$ pipet is 20 . The weight of the sediment in the sedimentation cylinder should equal the mean weight of the sediment determined from the first two withdrawals times the pipet-volume factor, which is $1.81 \mathrm{~g}$. The sedimentation-cylinder concentration is the weight of the water-sediment mixture, $500 \mathrm{~g}$, times $1,000,000$. The result is the concentration expressed in parts ppm: $3,620 \mathrm{ppm}$. The weight of the sediment from the pipet analysis is added to the weight from the other sample fractions, and the sum of these weights is the total weight of sediment for a sample. The results of the sample concentration are reported in $\mathrm{mg} / \mathrm{L}$ and are considered equal below 8,000 ppm or a conversion factor applied above this value (Edwards and Glysson, 1988).

A second method of obtaining the total weight of the sediment in the pipet also can be used. It can be used as an independent check on the accuracy of the first method. It also is useful for analyzing samples that have to be analyzed in sedimentation cylinders of less than $400 \mathrm{~mL}$ where three or more withdrawals are required to determine the particle size. In this second method, the first two withdrawals for concentration are not required as in the first method. After completion of the withdrawals for particle-size, the material remaining in the cylinder is dried and weighed. The weight from the cylinder is added to the weight from the particle-size withdrawals from the cylinder, and the weight correction for the dispersing agent is subtracted. 


\section{Quality-Control Measures}

- An aliquot sample is obtained for optimum cylinder size

- Glassware sequence is checked

- Withdrawal residues are weighed and stored electronically in the data file

- One in 10 samples is split into replicate samples and analyzed. Samples are reviewed by the laboratory chief.

- Concentration values are compared with those of replicate samples. Values within 10 percent are acceptable. If the difference is more than 10 percent, it is recorded on the sample results

- Reference samples are analyzed as scheduled

\section{Quality Assurance of Laboratory Procedures}

Internal QA procedures provide a guide for monitoring the quality of the data. These procedures include the analysis of QA samples, review of logbooks and computer procedures, training, equipment checks, data reviews, and documentation. If expected results are not obtained, immediate action is taken by the laboratory chief to identify and resolve the problem.

\section{Quality-Assurance Samples}

Normally, 5 percent of the samples analyzed by the laboratory will be QA samples inserted by the analyst or the laboratory chief in addition to the QA samples from the customers. These samples consist of field-collected replicate samples and blank samples. Blank samples are prepared from deionized water and will be distributed throughout the set of concentration-analysis samples. These samples will be clearly marked as QC samples. Analyses from the QC samples are reviewed by the laboratory chief; corrective actions are taken as required. The notes of these corrective actions are retained in the QC logbook.

The USGS Kentucky Water Science Center Sediment Laboratory participates in the Sediment Laboratory Quality Assurance (SLQA) program of the Office of Water Quality, Branch of Quality Systems, and the QA/QC exercises developed by the National Field Quality Assurance Program (NFQA), Branch of Quality Systems. (See USGS OSW Technical Memorandum No. 98.05, dated March 2, 1998, A National Quality Assurance Program for Sediment Laboratories Operated or Used by the Water Resources Division, online at http://water.usgs.gov/admin/memo/SW/sw98.05.html, accessed June 13, 2005.)

\section{Logbooks}

A logbook is maintained to document receipt of all samples by the laboratory. A summary sheet is prepared and attached to a hardcopy of sample results for each set of samples analyzed. The hardcopy of sample results is kept on file in the laboratory.

\section{Computer Procedures}

Documentation for the SLEDS software is available. Only the system administrator, sediment specialist, laboratory chief, and laboratory staff have access rights to the sediment-laboratory data files.

Data are archived on a hard-disc drive every 2 days. To avoid loss of data during a computer failure, a worksheet copy is made after each stage is completed in the concentration and sand/fine programs and a final formatted copy upon the completion of final analysis of the program. At the end of the third water year, which begins on October 1 and continues to September 30 of the next calendar year, the data files for the first water year 
are archived on magnetic tape. The magnetic back-up tapes are stored off-site for added security. Hard-copy data files are maintained on site for a period of 3 years.

\section{Training}

The training program for new staff members improves productivity and proficiency in sediment-laboratory techniques and the use of the computer programs. A typical training program is as follows:

During the first week, each employee is given a tour of the laboratory and shown the various analytical processes done in the laboratory. Procedures are demonstrated for the following: use of the laboratory equipment, use of the computer concentration program, and login of samples.

Each laboratory employee is provided with a copy of the "USGS Kentucky Water Science Center Sediment Laboratory Student/Employee Guidebook."

Each employee reads the QA plan to help provide a general understanding of the laboratory operations.

Each employee determines concentrations for 2 to 4 weeks under the supervision of the laboratory chief.

The work of the employee is reviewed carefully.

The next 4 to 8 weeks are used to increase proficiency and productivity of the employee. The work is reviewed weekly by the laboratory chief, and recommendations for further training are discussed with the Assistant Director, supervisor over the sediment laboratory operations.

\section{Equipment Checks}

A logbook is maintained for each balance, meter, and oven. A logbook also is maintained to record information relative to maintenance of apparatus and checking of deionized water and standard reagents.

\section{Data Reviews}

The analyst computes, initials, and dates all results. Analysis results are reviewed to assure they are complete and reasonable. The person responsible for QA activities provides a final review of the QC samples. Any corrective actions are included in a QA/QC logbook and in appropriate files.

\section{Documentation}

Basic references, a procedures manual, logbooks, and laboratory documents and correspondence are required documents needed to support the $\mathrm{QA} / \mathrm{QC}$ program of the sediment laboratory.

1. The basic references maintained in the laboratory are Fishman and Friedman (1985), Friedman and Erdmann (1982), Guy (1969), Knott and others (1992), and Matthes and others (1992).

2. A QA/QC manual specific to the USGS Kentucky Water Science Center Sediment Laboratory is required to describe the specific methods, procedures, instruments, and equipment that are used by the laboratory. The manual is updated periodically to document changes in equipment, apparatus, or facilities. Changes or modifications to analysis methods would only be made with approval by the USGS Office of Surface Water, Reston, Virginia.

3. Logbooks are required to provide documentation of maintenance and calibration of equipment, analysis of QA/QC samples, and necessary corrective actions would be logged, if needed.

4. The laboratory QA Plan, shipping and login records, copies of worksheets and analysis results, and related correspondence are the basic documents on file in the laboratory. 


\section{Data Management}

Data are stored in computer files and on paper analysis forms. Each type of documentation is vulnerable to potential data loss, and back-up measures are used. Electronic results are provided to the customers. Hard copies are maintained in the laboratory for three complete water years.

Data loss during analysis is decreased by printing working copies of each data entry stage for the samples. The working copies contain enough sample information to re-enter the files into the computer system, if necessary. The computer files are archived every other night. Only the sediment specialist, laboratory personnel, and the system administrator have access rights to edit analysis results in the computer files.

\section{Safety}

New laboratory employees receive a safety orientation by the USGS Kentucky Water Science Center Safety Coordinator. They each receive a copy of the USGS Kentucky Water Science Center "Emergency Procedures" handbook for reference, as needed. Laboratory safety and hazard-communication training is provided to all laboratory employees.

Safety concerns specific to the USGS Kentucky Water Science Center Sediment Laboratory are documented in the laboratory-safety handbook. The laboratory chief instructs laboratory personnel in the proper handling and storage of all glassware, containers, and laboratory equipment. Safety glasses, ear protection, nitrile gloves, and protective aprons are the basic safety equipment provided to laboratory employees. An eyewash station, safety shower, and first-aid kit are easily accessible.

Acid-rinsing of sample bottles must take place under the fume hood. The safety-related procedures are explained in the "Chemical Hygiene Plan of the USGS Kentucky Water Science Center Water-Quality Laboratory," which is maintained in the water-quality laboratory. This plan is designed to protect employees from overexposure to hazardous chemicals. No procedures take place in the laboratory without approval of the laboratory chief, and all chemicals must be stored in the certified chemical-storage cabinets provided.

\section{References Cited}

Acceptable methods for the analysis and reporting of sediment data by the USGS are provided in USGS Techniques of Water-Resources Investigations publications; in internal technical memoranda of the USGS Water Resources Discipline, the Discipline's Office of Surface Water and Office of Water Quality; and other publications. Reference is made to the following publications.

American Society for Testing and Materials, 1970, Standard Specifications for Sieves for Testing Purposes: American Society for Testing and Materials Standards, American Society Testing Materials Designation E-11-70.

American Society for Testing and Materials, 2002, D3977-97, Standard Test Methods for Determining Sediment Concentration Samples, online at <http://www.astm.org/cgibin/SoftCart.exe/DATABASE.CART/REDLINE PAGES/D3977.htm?E+mystore>, accessed June 13, 2005.

Edwards, T.K., and Glysson, G.D., 1988, Field Methods for Measurement of Fluvial Sediment: U.S. Geological Survey Open-File Report 86-531, $118 \mathrm{p}$.

Fishman, M.J., and Friedman, L.C., eds., 1985, Methods for Determination of Organic Substances in Water and Fluvial Sediments: U.S. Geological Survey Techniques of Water-Resources Investigations, book 5, chap. A1, $709 \mathrm{p}$.

Friedman, L.C., and Erdmann, D.E., 1982, Quality Assurance Practices for the Chemical and Biological Analyses of Water and Fluvial Sediments: U.S. Geological Survey Techniques of Water-Resources Investigations, book 5, chap. A6, 181 p.

Guy, H.P. 1969, Laboratory Theory and Methods for Sediment Analysis: U.S. Geological Survey Techniques of Water-Resources Investigations, book 5, chap. C1, online at <http://pubs.er.usgs.gov/pubs/twri/twri5c1>, accessed June 13, 2005. 
Inter-Agency Committee on Water Resources, Subcommittee on Sedimentation, 1958, Operator's Manual on the VisualAccumulation-Tube Method for Sedimentation Analysis of Sands, in Report K of A Study of Methods Used in Measurement and Analysis of Sediment Loads in Streams: Minneapolis, Minn., St. Anthony Falls Hydraulic Laboratory, $28 \mathrm{p}$.

Knott, J.M., Glysson, G.D., Malo, B.A., and Schroeder, L.J., 1993, Quality Assurance Plan for the Collection and Processing of Sediment Data by the U.S. Geological Survey, Water Resources Division: U.S. Geological Survey Open-File Report 92-499, online at <http://pubs.er.usgs.gov/pubs/ofr/ofr92499>, accessed June 13, 2005.

Knott, J.M., Sholar, C.J., Matthes, W.J., 1992, Quality Assurance Guidelines for the Analyses of Sediment Concentration by U.S. Geological Survey Sediment Laboratories: U.S. Geological Survey Open-File Report 92-33, online at $<$ http://pubs.er.usgs.gov/pubs/ofr/ofr9233>, accessed June 13, 2005.

Matthes, W.J., Sholar, C.J., George, J.R., 1992, Quality-Assurance Plan for the Analysis of Fluvial Sediment by Laboratories of the U.S. Geological Survey: U.S. Geological Survey Open-File Report 91-467, online at $<$ http://pubs.er.usgs.gov/pubs/ofr/ofr91467>, accessed June 13, 2005.

Tyler Industrial Products, 1976, Testing Sieves and Their Uses: Cleveland, Ohio, W.S. Tyler Co., Handbook 53, 48 p.

\section{Glossary}

The following are definitions of selected terms as they are used in this report; they are not necessarily the only valid definitions for these terms.

Accuracy-A measure of the degree of conformity of the mean value obtained by using a specific method or procedure with the true value. The concept of accuracy includes both bias (systematic error) and precision (random error) (Friedman and Erdmann, 1982).

Bias-A persistent positive or negative deviation of the mean value obtained by using a specific method or procedure from the true value. In practice, bias is expressed as the difference between the accepted true value and the mean value obtained by repetitive testing of a homogeneous sample (Matthes and others, 1992).

Precision-The degree of agreement of repeated measurements of a homogenous sample by a specific procedure, expressed in terms of dispersion of the values obtained about the mean value (Friedman and Erdmann, 1982).

Quality assurance-A term used to describe programs and the sets of procedures, including (but not limited to) quality-control procedures, which are necessary to assure data reliability. With regard to the analysis of fluvial sediment, the term includes practices used both by personnel outside as well as within the laboratory to assure the quality of laboratory data (Friedman and Erdmann, 1982).

Quality control—A term used to describe the routine procedures used to regulate measurements and produce data of satisfactory quality (Friedman and Erdmann, 1982).

Reference samples-Prepared sediment samples of known particle-size distribution or of a known weight. These samples are provided to laboratories or are produced in the laboratory as a part of the quality-assurance program.

Replicate sample-A second field-collected sample, collected using the same method of collection at the same location and at nearly the same time.

Sample blank-Samples consisting of deionized water that are inserted into the analysis routine. A sample blank verifies accuracy and precision of the laboratory balances and the quality of the deionized water and is a part of the quality-control program.

Split-sample - A part of a sample separately analyzed for comparison of results.

Standard solution-A fluid that is mixed to produce a specific value when it is tested with measurement instruments; it is used to check and calibrate the instruments.

Tare weight-The weight of a dry, clean, and empty sample container, crucible, or evaporation dish. 